ISSN 2414-987X
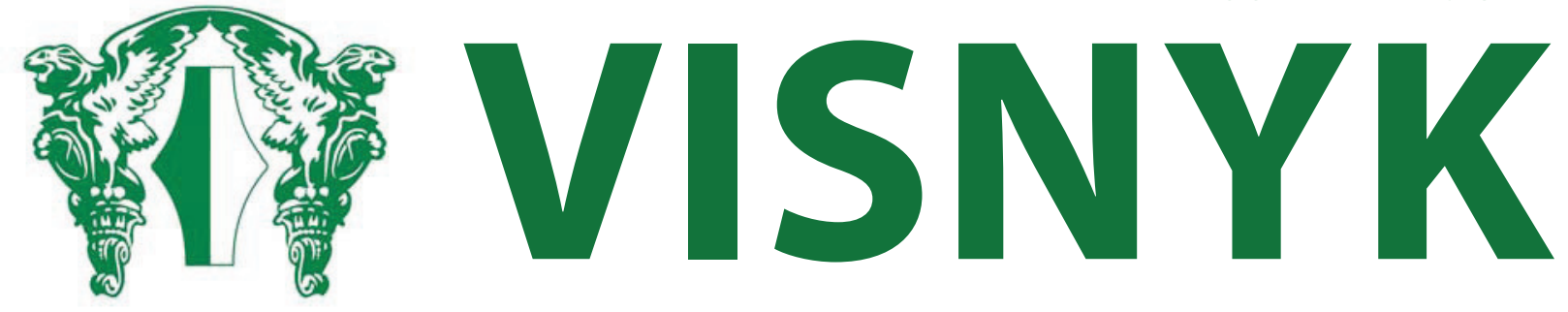

OF THE NATIONAL BANK OF UKRAINE

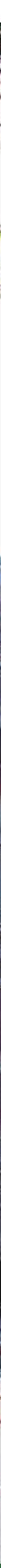

QUARTERLY RESEARCH

JOURNAL OF THE NATIONAL BANK OF UKRAINE

№ 240 June 2017 


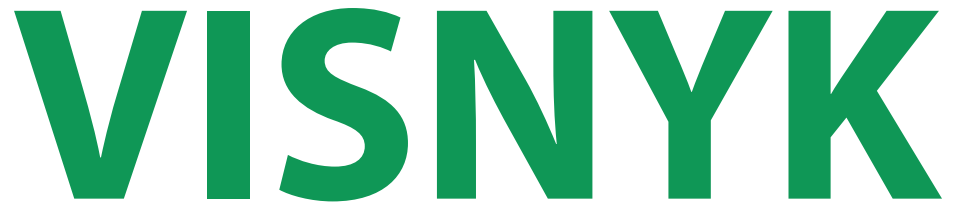

OF THE NATIONAL BANK OF UKRAINE № 240

Quarterly research Journal of the National Bank of Ukraine

Published since March 1995

\section{Editorial Board}

\section{Dmytro Sologub}

Chairman of the Editorial Board, Deputy Governor,

the National Bank of Ukraine

\section{Vitaliy Vavryshchuk}

Director of Financial Stability Department, the National Bank of Ukraine

\section{Yuriy Gorodnichenko}

Associate Professor, University

of California, Berkeley, PhD

\section{Oleksandr Petryk}

Doctor of Economics, Professor

\section{Inna Spivak}

Head of International Economy Analysis Unit of Monetary Policy and Economic Analysis

Department, the National Bank of Ukraine, Doctor of Economics

\section{Sergiy Nikolaychuk}

Deputy Chairman, Director of Monetary Policy and Economic Analysis Department, the National Bank of Ukraine, PhD

\section{Oleksiy Kryvtsov}

Director in the International Economic Analysis Department, Bank of Canada, PhD

\section{Tom Coupe}

Associate Professor,

University of Canterbury, PhD

\section{Viktor Koziuk}

Head of Economics Department at Ternopil National Economic University, Member of Council of NBU,

Doctor of Economics, Professor

\section{Andriy Tsapin}

Deputy Head of Research Unit of Monetary Policy and Economic Analysis Department, the National Bank of Ukraine, PhD

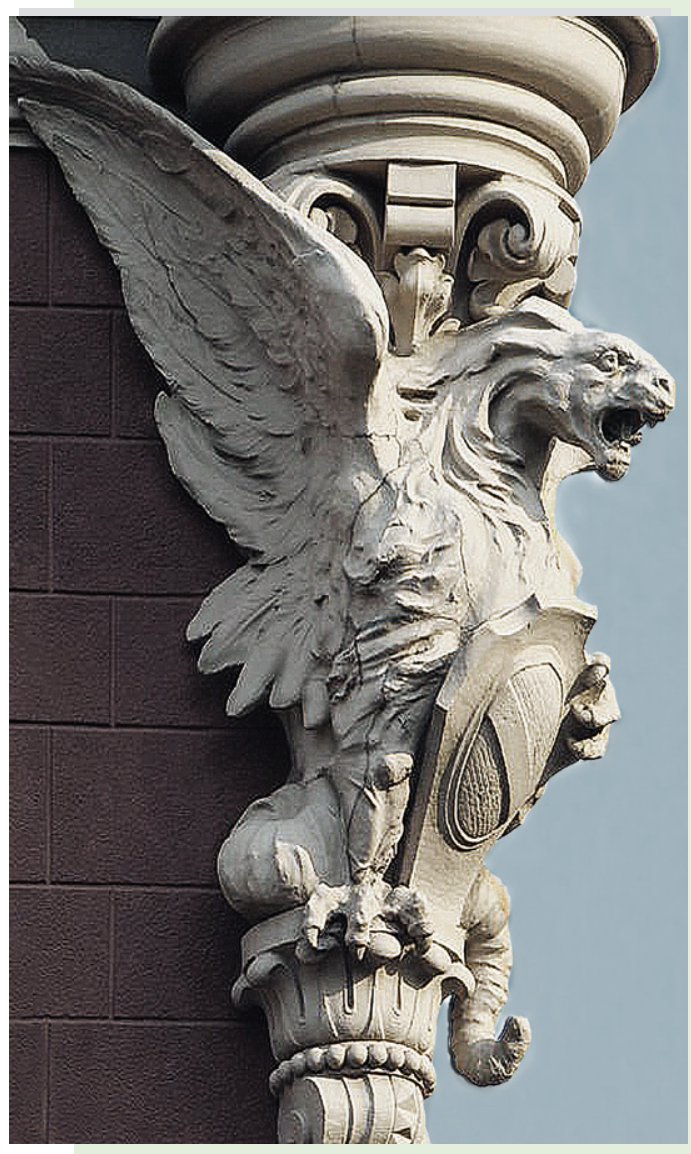

Founder and publisher:

National Bank of Ukraine

Editorial Board ensures compliance with ethical standards of publishing

For reprinting materials published herein the reference to the journal "Visnyk of the National Bank of Ukraine" is compulsory

The Editorial Board can publish materials being under discussion, not sharing the author's opinion

The author bears responsibility for the accuracy of the materials 


\section{PREFACE OF THE CHAIRMAN OF THE EDITORIAL BOARD}

\section{Dear readers,}

The current issue of the journal presents to your attention three empirical and applied studies, which have genuine policy implication on both macro- and micro- levels. In particular, our authors (1) address the issues about how to measure empirically financial stress endured by the financial system, (2) suggest a methodology for projecting credit facility exposure, and (3) explain the causes for the public debt growth in Ukraine through the evolution of fiscal policy regimes.

The first article of the issue, A Financial Stress Index for Ukraine by Lesia Tyschenko and Attila Csajbok, aims at providing a comprehensive analysis of the state of the financial system and its sensitivity to financial shocks. The authors argue that the Financial Stress Index that has been discussed in the paper can help recognize financial crises and may be used for assessing the effectiveness of anti-crisis measures.

The next article titled Predicting the Utilization Rate and Risk Measures of Committed Credit Facilities by Ihor Voloshyn sets fortgh a comparatively simple method for projecting the expected amount of credit facilities. This approach, according to the author, can be applied to estimate liquidity needs and loan losses for provisioning, as well as capital requirements.

Finally, in his research of Fiscal Policy Reaction Function and Sustainability of Fiscal Policy in Ukraine, Artem Vdovychenko analyzes the consequences of switching regimes in fiscal policy for accumulation of public debt. The author demonstrates that the fiscal policy in Ukraine asymmetrically reacted to business cycle: it was not prudent enough during the boom stage and remained neutral in recession. In particular, budget deficit was sensitive to debt-to-GDP ratio in 1998-2015 but at high levels of debt-to-GDP ratio fiscal policy switched episodically to an active regime when government applied intensively countercyclical measures.

The articles published in the current issue of our journal will draw your attention to the specific challenges faced by economic agents, providing a better insight into how the financial system is functioning under disturbances and how one can gauge the impact of the stress. We encourage you to engage in your own research and are prepared to provide a platform for a professional discussion between academics, experts and policymakers on topical issues in the realm of economics, finance, and banking. Send us your insightful papers for publication in the NBU's Visnyk to journal@bank.gov.ua.

\section{Best regards,}

Dmytro Sologub 


\section{CONTENTS}

Lesia Tyschenko, Attila Csajbok

A Financial Stress Index for Ukraine

Ihor Voloshyn

Predicting the Utilization Rate and Risk Measures of Committed Credit Facilities

Artem Vdovychenko

Fiscal Policy Reaction Function and Sustainability of Fiscal Policy in Ukraine 


\title{
A FINANCIAL STRESS INDEX FOR UKRAINE
}

\author{
Lesia Tyschenko \\ National Bank of Ukraine \\ Email: Lesia.Tyschenko@bank.gov.ua \\ Attila Csajbok ${ }^{1}$ \\ The World Bank, \\ Vienna Financial Sector Advisory Centre (FinSAC) \\ Email:acsajbok@worldbank.org
}

\section{ABSTRACT}

In this paper, we develop a daily Financial Stress Index (FSI) for the comprehensive quantitative measurement of the degree of stress in Ukraine's financial system. We use 14 individual indicators grouped into four sub-indices - the banking sector, corporate debt, government debt, and the foreign exchange market - to construct the FSI. The index measures the level of stress and vulnerability of the financial sector and enables to compare this level at current moment with its dynamic in the past. The FSI can signal the start of a financial crisis and can be used to assess the effectiveness of anti-crisis measures.

\section{JEL Codes: G01, G10, G20, E44}

Keywords: financial stress index, financial system, financial stability, financial crises

\section{INTRODUCTION}

Since the establishment of financial markets, financial crises have occurred periodically. The most recent crises have shown that an accurate method for assessing the degree of stress is essential to properly monitoring the state of the financial sector. Therefore, international financial institutions, central banks, researchers, and some major financial market players have created various indicators that assess the level of economic stress. The most well-known indicators are financial stress indices (FSIs).

Hakkio and Keeton (2009) proposed five key features of financial stress:

- Uncertainty about fundamental asset value and high volatility of market prices;

- Chaotic behavior by investors;

- Informational asymmetry;

- A sharp increase in risk or uncertainty;

- Low liquidity of the financial system.

Based on those criteria, financial stress can be defined as a state of uncertainty for financial system participants that leads to losses in asset values and in economic activity. Estimating stress levels at a given time has proven difficult, which has resulted in the need to quantify it.

Therefore, the main purpose of a Financial Stress Index (FSI) is to measure the current state of stress in the financial system using various indicators for different financial segments into a single quantitative statistic. The index allows policymakers to monitor the state of the financial system and to use it as a complementary tool in macroprudential analysis and policy decisions. The FSI also aims to define the systemic nature of the stress and assess whether the financial stress requires special attention. Growth in the index measure is an argument for additional monitoring of developments in the financial markets. By identifying growth in financial stress (or an existing high level of stress), policymakers can halt the development of negative factors and act to mitigate the potential impact on the economy.

A financial stress index is also a useful visual display that can be presented to the public to underscore the necessity for policy changes.

${ }^{1}$ Views presented here are those of the authors and do not necessarily reflect the official view of the World Bank. 
In summary, the FSI can be used to:

- Measure the level of stress in the financial system;

- Assess the depth and duration of the instability on financial markets and the stress level relative to past crises;

- Identify the nature of the financial system's distress and its individual components (systemic or segment-specific);

- Help identify the appropriate policy tools for decision-making;

- Assess the effectiveness of crisis countermeasures.

The indicators used to measure the level of financial stress should be selected taking into consideration the specifics of the country, including the availability and quality of the input data. Ideally, the interpretation of the index should be straightforward and intuitive. When selecting input indicators, the behavior of the indicators and the final index must broadly correspond to an expert assessment of the degree of stress at various periods of time. In Ukraine's case, we selected a final set of indicators that generate an index that matches our understanding of the stress periods in Ukraine's financial sector over the past decade. The National Bank of Ukraine's Financial Stress Index (FSI) consists of four sub-indices that reflect the banking sector, the markets for corporate and government debt, and the FX market.

Each sub-index is weighted by the size of the respective financial market relative to GDP. We built the index starting in 2008 and analyzed its past performance; we conclude that it closely matches our assessment of the state of the financial system. The NBU plans to maintain the FSI and regularly publish its performance in its Financial Stability Reports.

The purpose of this article is to provide an in-depth overview of the methodology for the Financial Stress Index (FSI) for Ukraine.

The article is structured as follows: chapter II reviews the growing literature on stress indices and their application and limitations; chapter III outlines the methodology used in building Ukraine's FSI; chapter IV provides an analysis of the evolution of Ukraine's FSI and its sub-indices over the past decade; and chapter $\mathrm{V}$ concludes.

\section{REVIEW OF THE LITERATURE: THE EMERGENCE AND EVOLUTION OF FINANCIAL STRESS INDICES}

Global financial markets have been turbulent in recent decades. In response to major financial crises in developing and advanced countries, policymakers and researchers have invested substantial resources in quantifying the degree of stress in the financial sector to understand the degree of stress relative to past crises. These efforts have resulted in various financial stress indicators - indices that track developments in the financial sector over a long period.

Initially, methodologies relied predominantly on one variable to measure the level of financial stress. For instance, the slope of the yield curve, the spread of 10-year treasury notes over the federal funds rate, the M2 money supply, or the shortterm credit spread as described by Estrella, Hardouvelis (1990), Freidman, Kuttner (1992). The Chicago Board of Exchange established the popular Volatility Index (VIX) based on equity option prices, which still fails to capture the degree of stress for the entire financial system.

In 2000, Bordo, Dueker, and Wheelock attempted to develop an index that would combine both quantitative and qualitative data. Their index, covering the 1870-1997 period, brought together a summary of business and bank bankruptcy rates, ex-post real interest rates, and interest rate quality spreads. A qualitative index based on descriptive sources was used to estimate data for the 1790-1869 period that lacked statistical records. To test the methodology, the qualitative index was extended to 1997 and an empirical model proved accurate based separately on the qualitative and quantitative indices. However, since the index was based on annual data, it was useful to analyze past trends, but its application in analyzing the current situation is limited.

The financial stability index built by investment bank J.P. Morgan uses different components of global risk - liquidity and credit and volatility risk - and combines them into a single index (LCVI). Liquidity risk is calculated based on the spread between on-the-run and off-the-run US Treasury bonds and US swap spreads; credit risk is measured by the spread between corporate 10 -year bonds over U.S. Treasuries; and volatility risk is based on the volatility of currency and options markets. This index is often used to determine the level of risk in global financial markets (International Monetary Fund, 2002, 2003a).

The lack of methods for measuring stress levels in the whole financial system was one of the most significant limitations of these indices. A new generation of financial stress indices were developed in the 2000s, aiming to embrace a much broader set of financial market data.

The Bank of Canada in 2003 introduced the first inclusive financial stress index to measure stress across the entire Canadian financial system. The new methodology marked a breakthrough and was further improved in 2006 by Illing and 
Liu. The Canadian index was built on eleven financial system variables (sub-indices) that covered the markets considered most important for the stability of the financial system: the banking sector, equity markets, bond markets, and foreign exchange. The sub-indices were weighted by the relative size of the respective market segments. The model was tested on several aggregation methodologies: factor analysis (principal components), econometric benchmarking, and generalized autoregressive conditional heteroskedasticity (GARCH) modeling. A credit weighting approach was used due to its best fit with the results of a qualitative survey by the Bank of Canada that looked at market participants' perceptions of periods of financial stress in Canada. This index was the first to cover most of the financial system and it became an inspiration for many financial stress indices developed later.

The global financial crisis of 2007-2009 and the European sovereign debt and banking problems that began in 2010 underscored the acute need for assessing the level of financial stress and calculating an FSI. The crises prompted academics and practitioners to intensify their efforts to develop appropriate measures.

The Federal Reserve Banks of the U.S. developed several financial stress indices to measure financial stress in the U.S.: the Federal Reserve Bank of Kansas City's Financial Stress Index (KCFSI) in 2009, the Federal Reserve Bank of St. Louis' Financial Stress Index (STFSI) in 2010, and the Federal Reserve Bank of Cleveland's Financial Stress Index (CFSI) in 2011.

Hakkio and Keeton (2009) used monthly data to construct the KCFSI. They used several criteria to select 11 indicators that reflect the key features of financial stress. "Each indicator had to represent features of financial stress - to reflect prices or yields on financial markets, because market prices and yields embody the largest amount of information and are the quickest to reflect changes in financial conditions; to be available on a monthly basis, so that a monthly financial stress index could be constructed; to be available at least since 1990, in order to assess the ability of the KCFSI to identify past episodes of financial stress." ${ }^{2}$ A principal component analysis (PCA) approach was used to aggregate the stress indicators. While the KCFSI relies on monthly data, all the processes sped up significantly during periods of severe stress, as was the case with the Bear Stearns and Lehman Brothers failures. In this respect, an index that quickly reflects market developments, ideally in real time, would be preferable.

This limitation prompted the Federal Reserve Bank of St. Louis to create a weekly financial stress index in 2010. The calculation of the index uses seven interest rate series, six yield spreads, and five other financial indicators, all of which are available back to 1993. The STLFSI and the KCFSI both use principal component analysis for aggregation. However, the STLFSI has an advantage in that its weekly basis allows it to reflect the current state of the financial system.

The Cleveland Fed's Financial Stress Index (CFSI) was developed in 2009 by M. Oet, T. Bianco, et al. and published in 2011. The index is based on daily financial market data to allow current stress levels to be assessed. The CFSI is based on 11 indicators covering four financial sectors: credit markets, equity markets, foreign exchange, and interbank markets. These sectors offer extensive coverage of the financial system, and stress in any of them can spread to the entire financial sector. A dynamic weighting method was used to capture changes in the relative importance of each of the four sectors.

Cardarelli, Elekdag, and Lall (2009, IMF) developed a financial stress index for advanced economies (AE_FSI). They explored stress episodes in 17 economies from 1980 to 2008. For every country, the index was calculated as a weighted average of three sub-indices: the banking sector, fluctuations in the cost of capital, and foreign exchange. Unlike the KCFSI, STLFSI, and Bank of Canada indices, which use principal components to determine the variable coefficients, the variables in the AE_FSI are standardized and assigned equal weights. Episodes when the AE_FSI diverges positively by more than one standard deviation from its historical mean value were identified as periods of financial stress. The authors also examined the correlation between financial stress and economic recessions. One of their conclusions is that episodes of financial turmoil and stress for banks are deeper and longer during economic downturns than episodes caused by turbulence in securities markets or foreign exchange markets. Economic recessions not connected with banking stress usually last half the time, or less.

Expanding the sample to 25 developing countries, Balakrishnan, Danninger, Elekdag, and Tytell (2009) improved the methodology and developed the Emerging Country Financial Stress Index (EM_FSI). This research allowed an exploration of the transmission channels of financial stress between advanced and developing economies, improved the quality of calculations, allowed a more accurate determination of stressful events, and provided the possibility of analyzing which factors - including common regional factors - led to increases in stress levels in developing economies.

In 2009, the European Central Bank developed its own financial stress index. The index applied to a sample of 28 counties, 10 classified as advanced economies and 18 as developing countries. The raw financial market data used by the ECB was standardized, log-transformed, and aggregated for three key markets: fixed income, equity, and foreign exchange. The most noteworthy contribution of the ECB index was that it also created the Global Index of Financial Turbulence to evaluate the average degree of stress in the world's most advanced economies.

In 2011 especially, central banks continued researching the topic of financial stress. In particular, Slingenberg and Haan (De Nederlandsche Bank, the central bank of the Netherlands) developed a financial stress index for 13 OECD countries. In 2015,

${ }^{2}$ Hakkio, Keeton(2009). Financial Stress: What Is It, How Can It Be Measured, and Why Does It Matter? https://core.ac.uk/download/pdf/6592699.pdf. 
they extended the coverage of the index to 29 countries. The authors intended to determine the key indicators for measuring financial stress. The variables they used were standardized by subtracting the mean and dividing by the standard deviation. The index was constructed as the un-weighted sum of standardized variables. The authors also attempted to establish a method for forecasting financial stress based on macro-financial variables. The results proved that accurately predicting financial stress in general is difficult, with the exception of credit growth, which has good predictive ability for most countries. At the same time, some variables that are acceptable as predictive variables in certain economies fail to produce accurate forecasts in other cases.

Haefcke and Skarholt of the Riksbank of Sweden built the Swedish Financial Stress Index (SFSI) using 14 daily indicators aggregated into five sub-indices: money markets, bond markets, the foreign exchange market, equity markets, and the banking sector. These sub-indices were weighted by the size of the respective sector in the financial system and their time-varying cross-correlation matrix. This aggregation method was eventually selected by comparing the output with the results of expert surveys.

Hollo, Kremer and Lo Duca of the ECB developed and introduced in 2012 a new weekly index, the Composite Indicator of Systemic Stress (CISS). The index is important because it reflects the current stress level in the financial system of the euro area. The CISS index marked a methodological breakthrough by using portfolio theory to aggregate five sub-indices, which, in turn, are built on 15 independent financial indicators. The aggregation involves time-varying cross-correlations between sub-indices, which yields a higher index level when the stress manifests itself across several markets simultaneously. The index therefore reflects the notion that financial stress is more likely to be systemic if it spreads to several markets; systemic financial stress puts the entire economy at greater risk of instability.

To summarize, the research in measuring the level of stress in the financial system has advanced significantly. The starting point was a simple single parameter index or indices for single markets. More recent approaches have relied on a set of variables that covers most of or the entire financial system. Index aggregation techniques have also varied - from equal weightings to weightings based on the relative size of market segments or a principal component analysis.

In building our FSI for Ukraine, we strive to develop a composite indicator covering several financial market segments, in-line with the findings and recommendations of recent research papers.

\section{CONSTRUCTING A FINANCIAL STRESS INDEX FOR UKRAINE}

The National Bank of Ukraine (NBU) initiated the development of a Financial Stress Index (FSI) for Ukraine to assess the degree of stress in the country's financial system and compare it to the historical long-term average. The index is built on daily data. The FSI calculation methodology is based on the methodologies applied in other countries, but adjusted to the countryspecific features of Ukraine's financial system. The key constraint is the limited availability of good-quality, high-frequency indicators with long observation periods. Another challenge is the low liquidity of some of the local financial markets; certain indicators can change abruptly and significantly as markets remain extremely sensitive to external and internal shocks.

- The domestic equity market is extremely small (UAH 14 billion in turnover in 2016, 0.6\% of GDP). In contrast, the government bonds section of the stock exchange is significant (UAH 211 billion, 9\% of GDP).

- The Ukrainian hryvnia is a volatile currency that is dependent on the balance of payments and sensitive to the frequent political and social stresses, as well as abrupt changes in sentiment by the population, which uses foreign currency as a store of value.

- Ukrainian debt securities have been among the highest-yielding and riskiest papers in the global investment universe.

Considering the above factors, certain indicators that are used widely in other countries are inappropriate to be included in Ukraine's FSI.

The work to establish the Financial Stress Index is divided into three stages:

- Selecting sub-indices and their components (indicators);

- Normalizing the indicators;

- Weighting the sub-indices to generate the FSI.

\section{Selecting sub-indices and their components (indicators)}

The construction of the FSI starts with the selection of sub-indices that, after weighting, provide a comprehensive measure of stress in the financial sector at a given time. Each sub-index is designed to reflect the state of the respective financial market segment. Each sub-index is based on individual financial market indicators. Ideally, at least three indicators are used; if some 
were to be used alone, they may fail to properly capture changes in market conditions. Taking an average of at least three variables provides a more robust and reliable assessment. To select a proper set of relevant sub-indices and their components, we analyzed the historical behavior of the different indicators and chose those whose performance fits with the different stages of past financial crises. In addition, the availability of daily data was an important criterion in selecting indicators.

We construct four sub-indices, each capturing the state of one segment of the financial market: the banking sector, corporate securities, government debt, and the foreign exchange market. Each sub-index is calculated as a simple average of the normalized individual indicators. These four sub-indices are then aggregated into a single FSI through a specific weighting approach (described later).

We use a daily time series for the 14 individual indicators starting from 2008 and update them on a regular basis. If an indicator is missing data, the last available value is used.

\section{Components of the banking sector sub-index:}

- Change in the overnight interbank rate. ${ }^{3}$ During periods of stress, interbank market rates rise as banks lend less to each other due to liquidity constraints and a higher bankruptcy risk.

- Liquidity of the Eurobonds of large Ukrainian banks, as measured by the average bid-ask spreads. The data is based on bonds issued by Oschadbank, Ukreximbank, First Ukrainian International Bank, and PrivatBank (until the bail-in in mid-December). ${ }^{4}$ The bid-ask spread reflects difficulties in pricing Eurobonds due to uncertainty and therefore represents a good indicator of banking market conditions. The higher the spread, the higher the level of stress in the banking sector.

- Bank liquidity - the total negative deviations from the double of the minimum instant liquidity requirement $(2 * 20 \%=$ $40 \%),{ }^{5}$ weighted by the share of deviating banks of total banking sector liabilities. The floor ratio is doubled because the floor is rarely binding and most banks easily comply with the ratio. The threshold is increased (doubled) to better capture signs of liquidity problems building in the banking sector. The more liquidity (and less stress) in the banking sector, the lower this indicator.

- Households' confidence in banks - the percentage change in the stock of retail deposits over the 30 days prior to the calculation date, separately for hryvnia and foreign currency deposits (in dollar terms). Changes in hryvnia and foreign currency deposits are then weighted by their respective market shares. ${ }^{3}$ The higher the change, the higher the customer confidence in banks. Historically, during periods of banking sector vulnerability, trust in banks falls, and households scramble to withdraw deposits and keep their savings in cash. Therefore, this indicator is a negative value ('-'); lower confidence levels translate to a higher FSI value.

\section{Components of the corporate securities sub-index:}

- The premium corporates pay on debt relative to the government - the yield spread on Ukrainian corporate Eurobonds over sovereign Eurobonds. ${ }^{6}$ This value reflects the risk of the corporate sector relative to sovereign risk. The wider the spread, the higher the stress level in the corporate debt market.

- The Cmax indicator for Ukrainian stocks (Cmax $=1-\mathrm{Xt} / \max (\mathrm{XT}))$ shows the deviation of an index of stocks on a specified date from its maximum over the previous 12 months. This enables the identification of stock market declines/crashes by measuring the maximum cumulative loss over the past year. The PFTS Index is used for calculations before 2011 and the WIG Ukraine Index from the Warsaw Stock Exchange afterwards. ${ }^{7}$ The WIG Ukraine Index is appropriate because it tracks relatively liquid stocks of Ukraine-based companies listed in Warsaw. Ukraine's local stock market is almost non-existent and is subject to price manipulation. The higher the value of this indicator, the larger the decline on the stock market is in comparison with its rolling 12-month maximum.

- The volatility of Ukrainian stocks - the standard deviation of the values of stock indices over the 30 days prior to the calculation date. The PFTS Index is used prior to 2012 and the WIG Ukraine Index afterwards. ${ }^{7}$ Stock market volatility increases when uncertainty grows; changes in this measure are related to financial sector stress.

\section{Components of the government debt sub-index:}

- Sovereign risk - the spread between the weighted average yield of Ukrainian government Eurobonds and the yield on 10-year US Treasury bonds (US Treasury 10Y). ${ }^{6}$ This indicator reflects the riskiness of investments into Ukrainian sovereign debt. The higher the spread, the higher the risk level.

\footnotetext{
${ }^{3}$ Source: National Bank of Ukraine.

${ }^{4}$ Source: Bloomberg.

${ }^{5}$ Defined as the ratio of a bank's highly liquid assets to current liabilities, which must be not less than $20 \%$.

${ }^{6}$ Source: Cbonds.

${ }^{7}$ Source: PFTS and the Warsaw Stock Exchange.
} 
- The liquidity of Ukrainian government Eurobonds - a simple mean bid/ask spread of government-issued Eurobonds on a given date. ${ }^{8}$ In times of financial instability, the bid-ask spread on government bonds usually grows.

- Credit default swaps ${ }^{8}$ of Ukrainian sovereign bonds - reflecting the probability of issuer default perceived by the market, which correlates highly with financial stress levels.

\section{Components of the FX market sub-index:}

- Expectations of devaluation - the difference between the NDF (non-deliverable forward) UAH/USD 3M and interbank spot UAH/USD exchange rates adjusted for interest rate gaps between the Ukrainian interbank market (KievPrime3M) and the London interbank market (\$Libor3M), in percent. ${ }^{9}$ NDF contracts fix an exchange rate now for settlement at a future date (3M), therefore the difference between the NDF and spot rates (adjusted for interest rate differences) reflects market expectation of future UAH/USD moves. The higher the difference, the greater the expected depreciation for the hryvnia.

- The Cmax indicator for the interbank UAH/USD rate - calculated like the Cmax for Ukrainian stocks. ${ }^{10}$ The higher the value of the indicator, the weaker the hryvnia is relative to its strongest level over the preceding 12-month period.

- Volatility of the interbank UAH/USD rate - calculated like the volatility of Ukrainian stocks. ${ }^{10}$ In times of financial stress, exchange rate volatility is typically higher.

- FX market imbalances - the net purchase/sale of foreign currency by the NBU on the interbank FX market on the calculation date. ${ }^{10} \mathrm{~A}$ net sale of foreign currency by the NBU is a signal of financial stress as this usually indicates a shortage of foreign currency on the market.

\section{Normalizing indicators}

Indicators with different units of measurement need to be restated to create comparable input data that will allow them to be averaged. This is done by normalizing the indicators.

Normalization can be done in several ways, each with relative advantages and disadvantages. Hakkio and Keeton (2009), Slingenberg and Haan (2011), etc., used the standard deviation approach: the sample mean is subtracted from the raw score of the individual indicators and the difference is then divided by the sample standard deviation. This method has significant limitations. First, the sample mean and the standard deviation must be revised for new data observations, which required past values to be recalculated. Second, normalized indicators can have different scales, making the construction of a composite index a challenge.

Illing and Liu (2003); Oet and Bianco (2011); Haefcke and Skarholt (2011); Hollo, Kremer, and Lo Duca (2012) used a variety of other methods summarized in the table below:

\section{Table. Normalization methods}

\begin{tabular}{|l|c|c|}
\hline \multicolumn{1}{|c|}{ Method } & Pro & \multicolumn{1}{c|}{ Con } \\
\hline $\begin{array}{l}\text { Cumulative distribution } \\
\text { function (CDF) }\end{array}$ & $\begin{array}{c}\text { (0.1) range, } \\
\text { more historically stable }\end{array}$ & $\begin{array}{l}\text { noisy, distorts relative stress size (especially } \\
\text { on small samples), sensetivity to outliers }\end{array}$ \\
\hline Variance-equal & no distortion & historically unstable, accepts negative values \\
\hline Min-Max Range & (0.1) range, no distortion & may be too sensitive to outliers \\
\hline
\end{tabular}

We chose the min-max range normalization method to calculate our FSI. This method yields numbers from 0 to 1 , a clear advantage - the index can be interpreted easily by non-professional users. Other methods yield outcomes from -1 to 1 , and negative values can be mistakenly perceived as adverse or reflecting stress in the financial system. However, the method has one drawback - if new values for certain indicators exceed the historical highs or lows, the entire series of normalized values must be recalculated. The Ukrainian financial system has undergone two enormous financial crises since 2008, including one related to a serious geopolitical conflict, and new shocks that would drive the key indicators above previous maximums are unlikely in the foreseeable future.

Each indicator is normalized using the formula:

$$
V^{\prime}(i)=\frac{V(i)-\min (V(i))}{\max (V(i)-\min (V(i))}
$$

\footnotetext{
${ }^{8}$ Source: Bloomberg.

${ }^{9}$ Source: Cbonds, National Bank of Ukraine (interbank rate).

${ }^{10}$ Source: National Bank of Ukraine.
} 
where $\mathrm{V}(\mathrm{i})$ is the value of the raw indicator at day $\mathrm{i}, \mathrm{V}^{\prime}(\mathrm{i})$ is the value of the normalized indicator, and the min and $\max$ operators use the whole available sample.

The normalization process yields results ranging from zero to one for the indicators, the sub-indices, and the FSI itself. This allows us to explore and analyze the level of stress in the whole financial system, in individual segments, and across different indicators. The closer the value to 1 , the higher the stress level at a given moment.

\section{Aggregating the sub-indices into the FSI}

Next, the weights used to pool the four sub-indices into the Financial Stress Index must be determined. Since the financial market segments represented by the sub-indices carry different importance for the Ukrainian economy, the sub-indices must have weights that accurately capture the relative significance of the respective market segments. We use a weighting approach based on the size/relative importance of the various segments in Ukraine's financial system. We calculated the size of each segment relative to GDP, using the following metrics to approximate sizes:

1) Banking sector - the total volume of loans to residents (non-financial corporations and households);

2) Corporate securities - the sum of the stock market capitalization and the volume of the corporate bond market;

3) Government securities - the volume of outstanding local currency bonds and sovereign Eurobonds;

4) FX market - the volume of foreign currency securities issued by residents (both in the domestic and external markets) and foreign currency loans to residents.

Based on this exercise, we assigned the following weights to each segment / sub-index:

1) Banking sector: 0.3;

2) Corporate securities: 0.1;

3) Government securities: 0.25 ;

4) FX market: 0.35 .

\section{THE FSI CAPTURES PERIODS OF FINANCIAL TURBULENCE IN UKRAINE WELL}

Figure 1. Ukraine's Financial Stress Index

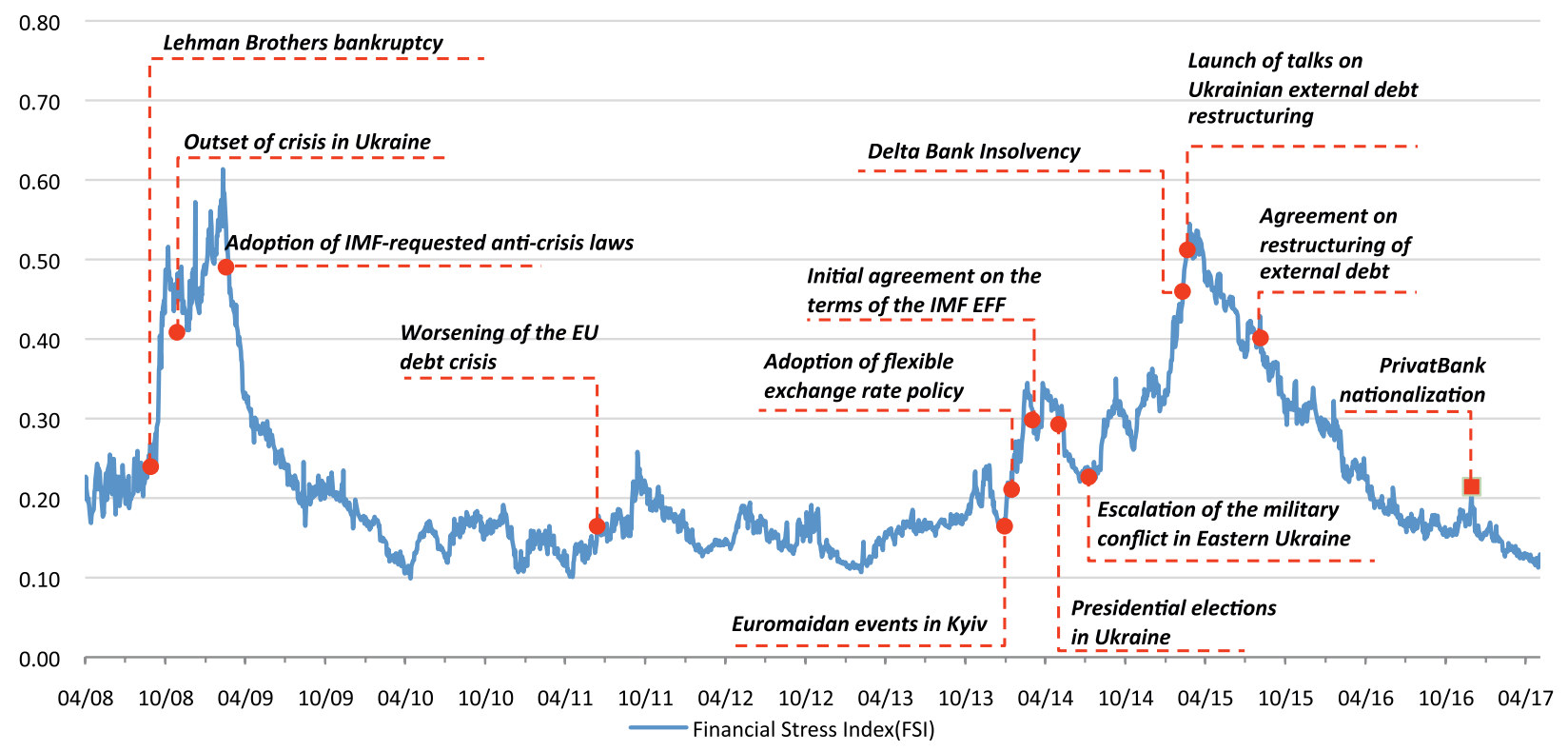


The data available allows the FSI for Ukraine to be measured starting in April 2008. The FSI was very volatile as the world approached the global financial crisis (Figure 1). The crisis clearly broke out with the collapse of Lehman Brothers in September 2008. Global markets reacted immediately, as did the Ukrainian market as seen by the significant spike in the FSI. With additional shocks to the local financial market, the index continued to rise until March 2009. That month the FSI reached its peak value over the eight-year observation period. The financial stress had multiple origins at the time - an abrupt decline in exports, the closure of external capital markets for Ukrainian companies, and, subsequently, a currency crisis. All these undermined the solvency of the government and private borrowers, driving yields on public and private debt up. The growth in the FSI was therefore driven by turbulence in each of the four component sub-indices (Figure 2). The crisis lasted for about a year and the index returned to its pre-crisis level in Q4 2009. The situation normalized following the stabilization and global financial and commodity markets recovered gradually. Many private borrowers (Eurobond issuers) had to restructure debt to ease liquidity pressures amid the ongoing crisis. The IMF program with Ukraine also helped ease pressures, even if temporarily.

\section{Figure 2. FSI sub-indices for Ukraine}

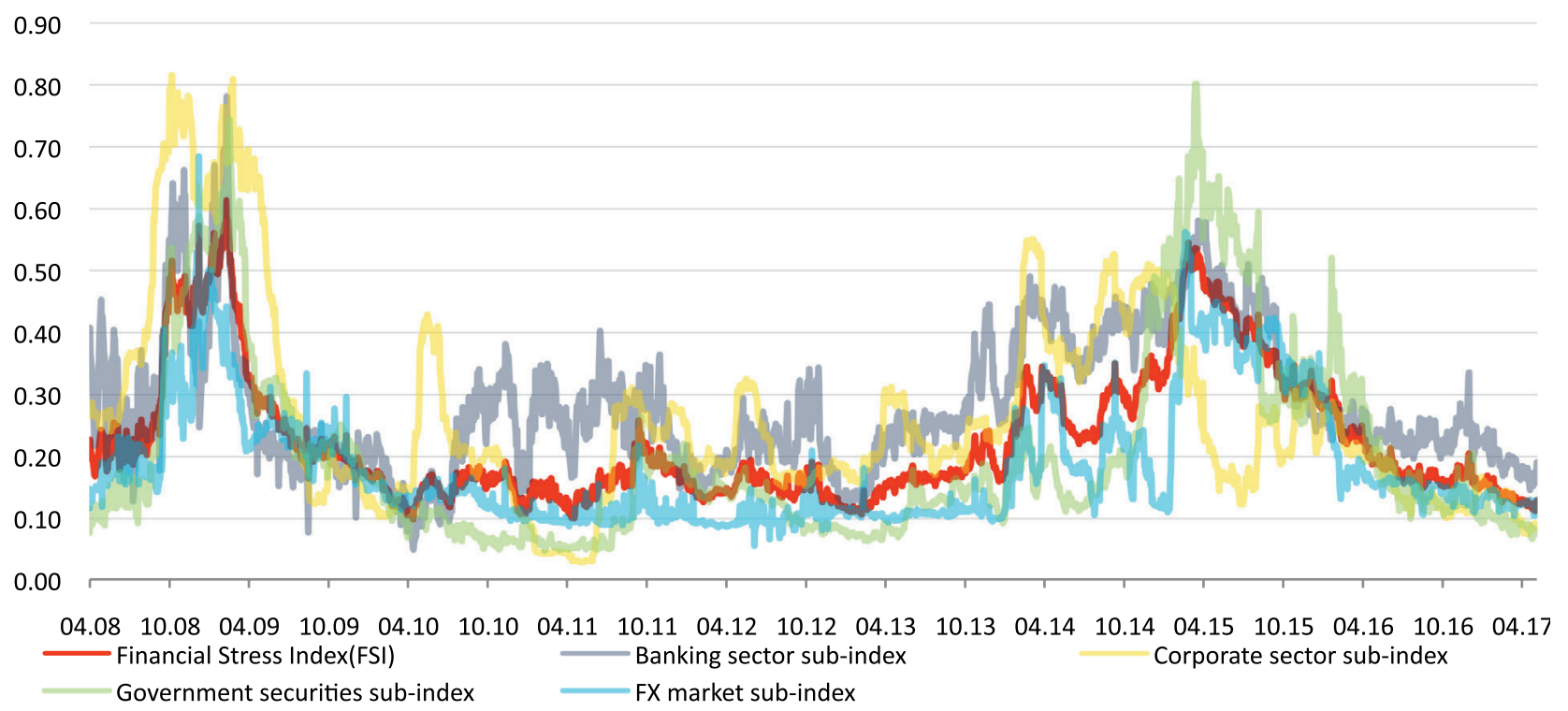

Source: NBU.

The FSI remained volatile but at relatively low levels from early 2010 until a visible spike in Q4 2011, largely a reflection of the unfolding European sovereign debt crisis, which was contained by end-2013.

The most recent period of severe stress started in late 2013 when the Euromaidan (civil protest) led the then-president to flee and the government to resign. The subsequent invasion by Russia, annexation of Crimea, and military conflict in Eastern Ukraine fueled the largest and deepest economic and financial crisis in two decades. This period saw a sequence of severe economic challenges and policy responses. The exchange rate depreciated sharply as Ukraine lost a third of its export potential in the occupied territories. The NBU abandoned its fixed exchange rate policy and introduced a floating rate policy to ensure that external shocks are absorbed via exchange rate adjustments. The banking sector experienced a long and severe run on deposits - the population withdrew more than $20 \%$ of retail hryvnia deposits and $60 \%$ of foreign currency deposits. This caused the banking sector sub-index to rise substantially. All government Eurobonds were restructured, with a $20 \%$ haircut on the principal in exchange for VRI (Value recovery instruments) and a significant extension of maturity. The private sector followed suit, restructuring nearly all outstanding external debts. Naturally, yields on sovereign and private debt surged during 2014-15. In the latest crisis, the FSI did not reach the peak value recorded in March 2009. However, the crisis was long; the index returned to its pre-crisis level only after three years.

The most recent temporary spike in the FSI was caused by uncertainty ahead of the nationalization of PrivatBank, Ukraine's largest bank, in December 2016. The index peaked on the day of the government's intervention into the bank and retreated relatively quickly in the following weeks. It is worth noting that the banking sector sub-index has been volatile nearly at all times. The sector has been vulnerable to minor and major shocks that affect the financial sector. This is a clear sign of the fundamental weakness of the Ukrainian banking sector prior to the NBU's massive clean-up of banks that began in early 2014. Now that the sector has been cleaned and is recovering, we expect a decline in volatility and in the level of the banking sector sub-index. 


\section{CONCLUSIONS}

Financial stress indices - composite measures of the degree of disruption in financial markets - have gained in popularity globally over the past decade. These indices usually serve as a single comprehensive measure of financial sector stress and are therefore easy to interpret. They provide a good indication of how the situation in the financial sector compares to previous periods and they serve as a gauge of the degree and duration of turbulence in the financial sector. The FSI for Ukraine is built on four sub-indices that capture the state of different segments of the domestic financial market. Each sub-index is, in turn, based on at least three indicators (14 in total) that quantify the turbulence in the respective segments. Retrospectively, the FSI for Ukraine is correlated well with a narrative account of developments in the financial sector and it seems to have captured all the major external or domestic shocks that were transmitted to the financial system. The FSI serves as a good proxy for the degree of stress facing the Ukrainian economy at any given moment of time and thus can be used by policymakers as a monitoring tool.

\section{References}

- Balakrishnan R., Danninger S., Elekdag S., Tytell I. (2009). The Transmission of Financial Stress from Advanced to Emerging Economies. Working paper, No. 09-133, International Monetary Fund, Washington D.C.

- Bordo M., Dueker M. Wheelock D. (2000). Aggregate price shocks and financial instability: an historical analysis. Working Paper, No. 7652, National bureau of economic research, Cambridge.

- Cardarelli R., Elekdag S., Lall S. (2009). Financial Stress, Downturns and Recoveries. Working paper, No. 09-100, International Monetary Fund. Asia and Pacific Department.

- Grimaldi M. (2010). Detecting and interpreting financial stress in Euro area. Working Paper, No. 1214, European Central Bank (ECB), Frankfurt am Main.

- Haefcke S., Skarholt A. (2011). A Swedish Financial Stress Index. Stockholm School of Economics.

- Hakkio C., Keeton W. (2009). Financial Stress: What Is It, How Can It Be Measured, and Why Does It Matter? Economic Review, Second Quarter 2009, Federal Reserve Bank of Kansas City, pp. 5-50.

- Hollo D., Kremer M., Duca M. (2012). CISS - A Composite Indicator of Systemic Stress in the Financial System. Working Paper, No. 1426, European Central Bank, Frankfurt am Main. https://doi.org/10.2139/ssrn.1611717

- Illing M., Liu Y. (2003). An Index of Financial Stress for Canada. Working Paper, No. 2003-14, Bank of Canada. Ottawa.

- Kliesen K., Smith D. (2010). Measuring financial market stress. Economic synopses, No. 2, Federal Reserve Bank of St. Louis.

- Oet M., Eiben R., Bianco T., Gramlich D., Ong S. (2011). Financial Stress Index: Identification of Systemic Risk Conditions. Federal Reserve Bank of Cleveland. Cleveland.

- Slingenberg J., Haan J. (2011). Forecasting Financial Stress. Working Paper, No. 292, De Nederlandsche Bank, Amsterdam. https://doi.org/10.2139/ssrn.1951800 


\title{
PREDICTING THE UTILIZATION RATE AND RISK MEASURES OF COMMITTED CREDIT FACILITIES
}

\author{
Ihor Voloshyn ${ }^{1}$ \\ National Bank of Ukraine \\ Email: Ihor_Voloshyn@bank.gov.ua
}

\begin{abstract}
This study proposes a model for predicting the expected drawn amount of credit facilities. To model the committed credit facilities we rely on the conditional expected utilization rate derived from a joint truncated bivariate probability distribution. The expected monthly liquidity conversion factors for corporate credit lines are compared to actuals and the bivariate normal distribution is concluded to be appropriate for a practical estimate of the future utilization rate.
\end{abstract}

\section{JEL Codes: C58, G21, G32}

Keywords: utilization rate, committed credit facilities, exposure at default, credit conversion factor, liquidity conversion factor

\section{INTRODUCTION}

Committed credit facilities are key products offered by banks to corporate and retail clients, mainly in the form of irrevocable revolving lines of credit and current account overdraft facilities. Two important features of these products are the obligation by the bank to provide future commitments to the available credit and the right for clients to draw additional funds unless a credit limit has been reached. At the same time, the committed credit facilities can have a crucial impact on expected loan losses, capital, and liquidity ratios and a sudden drawdown in credit facilities creates both credit and liquidity risks. Because of the risks, the Basel Committee on Banking Supervision (BCBS), the European Banking Authority (EBA), the National Bank of Ukraine (NBU), and the new IFRS 9 establish rules for evaluating and recognizing credit facilities' risks (BIS, 2001, 2013; Regulation EU, 2013; NBU, 2016; IFRS 9).

This paper proposes a model for predicting the expected drawn amount of credit facilities based on the use of a conditional utilization rate derived from a joint truncated bivariate distribution.

The remainder of this paper is organized as follows: Section II outlines the target variables and model techniques used to estimate the expected drawn amount; Section III presents the approach to predicting the expected utilization rate based on a joint truncated bivariate distribution and examples of evaluating credit and liquidity risk measures; and Section IV provides the conclusions and direction for further investigation.

\section{LITERATURE REVIEW}

To predict the drawn amount of credit facilities, researchers have tested many different factors: the conversion factor, the utilization rate (limit usage), the change in utilization, and directly observed drawn amounts (Moral and de España, 2006; Taplin and al., 2007; Osipenko and Crook, 2015; Tong and al., 2016). However, there is no consensus among practitioners and researchers over which variables and techniques should be used for modelling.

The Basel Committee suggests using the Credit Conversion Factor (CCF) to calculate Exposure At Default (EAD) and a similar coefficient, the Liquidity Conversion Factor (LCF), to calculate the Liquidity Coverage Ratio (BIS, 2001, 2013). Therefore, the CCF is the ratio of the estimated Extra Drawn Amount $\left(E A D-B_{t}\right)$ during, according to Basel, the 12 months prior to default over the undrawn amount $\left(L-B_{t}\right)$ at current time $t$ (for instance, see Jacobs, 2009; Moral and de España, 2006):

${ }^{1}$ Acknowledgments. The author is very grateful to an anonymous reviewer for valuable comments and fruitful suggestions for improving the paper. 


$$
C C F=\frac{E A D-B_{t}}{L-B_{t}}
$$

where $E A D$ is the exposure at default, $L$ represents the credit limit, $B_{t}$ is the drawn amount of credit facilities at current time $t$. Note that under IFRS 9, the period of the $12^{\text {th }}$ month can be extended for the lifetime of a loan for certain types of impaired loans. The National Bank of Ukraine uses the CCF (NBU, 2016). The Liquidity Conversion Factor (LCF) differs from the CCF in that the extra drawn amount is estimated at a given time in the future. For instance, the LCF is predicted over a 30-day (monthly) horizon to estimate the Liquidity Coverage Ratio. It shows potential drawdowns as a percentage of off-balance sheet items (L-Bt) (BIS. 2013):

$$
L C F=\frac{E D A-B_{t}}{L-B_{t}}
$$

where EDA is the expected drawn amount at a given future time.

Thus, the credit facilities contain both on- and off-balance sheet items (Figure 1).

\section{Figure 1. The credit limit and the drawn and undrawn amounts of committed credit facilities}

Current, $t$

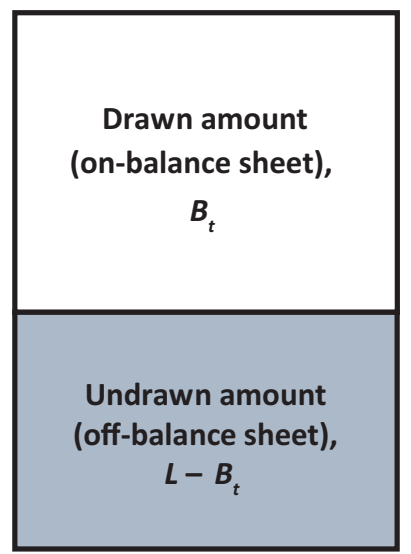

Developed by the author.
Future, $t+\tau$

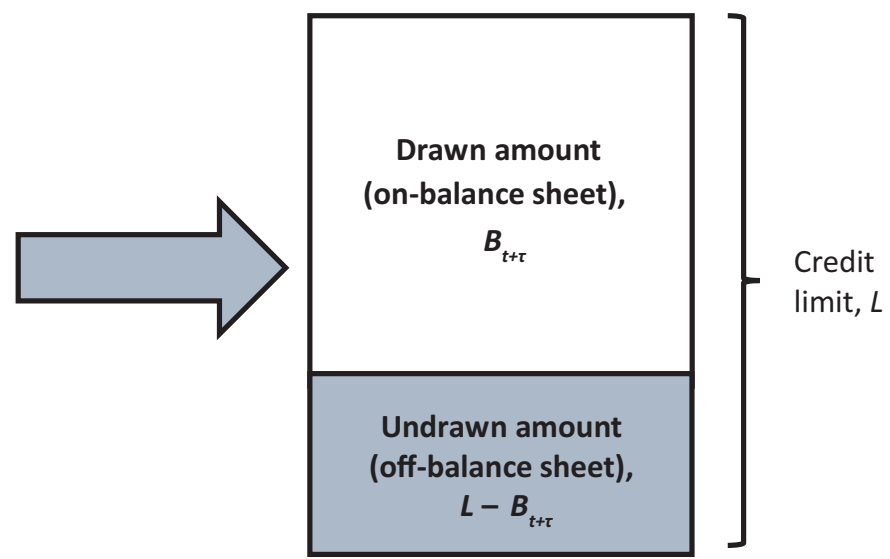

These conversion factors are transparent and logical and are easy to use in practice. Indeed, the drawn amount can increase in the future directly in proportion to the undrawn amount of credit facilities. This relationship is valid for a separate credit facility, but not true for all credit facilities. In fact, off-balance sheet items include credit commitments with different levels of limit usage. Meanwhile, the CCF approach contains a hidden assumption that the level of utilization of credit commitments is the same. As a result, the CCF approach can overestimate or underestimate risks. Nevertheless, Basel's CCF approach has motivated banks to deepen their understanding of their off-balance sheet risks. Usage of CCF and EAD has become so popular among banks that they are planning to use them with the transition to IFRS 9, even though the standard does not implicitly require its use (GPPC, 2016). Meanwhile, practitioners and researchers are faced with problems in directly and accurately estimating conversion factors. This has proved to be a difficult task, for several reasons. The distribution of the CCF is relatively complex and bimodal. It is not defined when the current drawn amount equals the credit limit. The CCF is not stable when the current drawn amount is close to the credit limit. It does not take into account changes in credit limit over time (Moral and de España, 2006). As a result, practitioners and researchers have started to seek alternate approaches. These include the direct investigation of the EAD (Kim and DeVaney, 2001; Taplin and al., 2007; Tong and al., 2016) and the use of new dimensionless target variables such as: 
- The utilization rate (Jacobs, 2009; Yang and Tkachenko, 2012):

$$
U_{t}=\frac{B_{t}}{L}
$$

that is, the ratio of the current outstanding drawn amount to the credit limit, and

- The change in utilization (Jacobs, 2009; Yang and Tkachenko, 2012):

$$
\Delta U_{t}=\frac{B_{t}-B_{t-1}}{L} \equiv U_{t}-U_{t-1}
$$

that is, the ratio of the change in drawn amount to the credit limit.

Both dimensionless target variables have a minimum of 0 and maximum of 1 , meaning its distributions are truncated. This creates difficulties in the use of standard estimation techniques. Numerous results of direct EAD estimates show that the EAD is directly proportional to the credit limit $L$ and has a weak relationship with the current drawn amount $B_{t}$ (for instance, Kim and DeVaney, 2001; Taplin and al., 2007). This proves the utilization rate plays a key role in predicting the drawn amount in the future. In contrast to CCF, the utilization rate $U_{t}$ is well-defined and stable given any outstanding drawn amount. It captures possible changes in the credit limit over time (Moral and de España, 2006). Therefore, the utilization rate is expected to have a better distribution than the CCF's bimodal distribution. Osipenko and Crook (2016) additionally argued that the utilization rate more deeply captures borrowers' behavior, banks' credit policies, and products' parameters. They stated that the prediction of the utilization rate instead of the drawn amount helps avoid possible disproportion in modelling.

The methodological efforts of practitioners and researchers have been predominantly directed at identifying more advanced:

- Univariate distributions for target variables that better describe empirical data. For instance, Tong and al. (2016) proposed a univariate mixture model with a zero-adjusted gamma distribution for the EAD distribution.

- Regression techniques to improve the prediction of drawdowns. For instance, Osipenko and Crook (2016) used advanced estimation techniques such as ordinary linear regression, beta regression, beta transformation plus general linear models, fractional regression, and weighted logistic regression.

Note that the use of univariate distributions does not provide an understanding of how the explanatory variables affect the expected drawn amount of credit facilities. For example, how the current level of the utilization rate influences on the future rate. Unfortunately, regressions only approximately represent the statistical dependence of the predictable and explanatory variables (Korns, 1968). The author did not find any work on the use of joint bivariate distributions for predicting drawdowns. As a result, the author chooses the utilization rate as the target variable and tests the alternative to regressions approach based on the joint truncated distribution of the future and current utilization rates to predict the expected drawn amount.

\section{MODELLING THE UTILIZATION RATE BASED ON DOUBLY TRUNCATED BIVARIATE PROBABILITY DISTRIBUTION}

Let us have historical long-time daily series of the current drawn (on-balance sheet items) and undrawn (off-balance sheet items) amounts of facilities (Figure 1). Knowing these series, we build the historical time series of the utilization rate $U_{t}$. Note that the statistical data should contain a large number of independent credit lines. Time periods should be chosen to include periods when credit limits were fixed. Knowing the series of two random variables $U_{t}$ and $U_{t+\tau^{\prime}}$ we find the joint probability distribution function $f\left(U_{t^{\prime}} U_{t+\tau}\right)$ doubly truncated in the square area: $0 \leq U_{t^{\prime}} U_{t+\tau} \leq 1$. Here we assume the joint bivariate probability distribution function is stationary. We are interested in finding the conditional expected utilization rate (exceeding the current utilization rate $U_{t}$ ) at a future time $(t+\tau)$ if the current utilization rate at time $t$ is given $U_{t}$ :

$$
U_{t+\tau}\left(U_{t}\right)=\mathrm{E}\left(U_{t+\tau} \mid U_{t}\right)
$$

Knowing the joint probability function $f\left(U_{t^{\prime}} U_{t+\tau}\right)$, we gain the conditional probability density function $f\left(U_{t+\tau} / U_{t^{\prime}}\right)$ of variable $U_{t+\tau}$ given $U_{t}$ : 


$$
f\left(U_{t+\tau} \mid U_{t}\right)=\frac{f\left(U_{t}, U_{t+\tau}\right)}{f\left(U_{t}\right)}=\frac{f\left(U_{t}, U_{t+\tau}\right)}{\int_{0}^{1} f\left(U_{t}, U_{t+\tau}\right) \times d U_{t+\tau}}
$$

Taking into account (6), the conditional expected utilization rate is given by:

$$
U_{t+\tau}\left(U_{t}\right)=\frac{\int_{U_{t}}^{1} U_{t+\tau} \times f\left(U_{t+\tau} \mid U_{t}\right) \times d U_{t+\tau}}{\int_{U_{t}}^{1} f\left(U_{t+\tau} \mid U_{t}\right) \times d U_{t+\tau}} \equiv \frac{\int_{U_{t}}^{1} U_{t+\tau} \times f\left(U_{t}, U_{t+\tau}\right) \times d U_{t+\tau}}{\int_{U_{t}}^{1} f\left(U_{t}, U_{t+\tau}\right) \times d U_{t+\tau}} .
$$

Therefore, the formula (7) predicts the conditional expected utilization rate at a future time $(t+\tau)$ given the current utilization rate $U_{t}$ at time $t$. Recall that in order to evaluate expected loan losses, Basel recommends calculating drawdowns on facilities over 12 months, but IFRS 9 requires doing this over the entire lifetime for certain types of impaired loans.

If we have the long time-series of data, we can analyze the joint distributions of pairs of $U_{t}$ and $U_{t+k \times \tau}$ and predict the expected utilization rate for moments in time: $1 \times \tau, 2 \times \tau, \ldots, k \times \tau, \ldots, K \times \tau$. Furthermore, we assume that $\tau=30$ days. Then $k$ denotes the number of month in the periods explored. If the time series is short we can apply the next recursive procedure. Let us have only one distribution of pairs $U_{t}$ and $U_{t+\tau}$. In this case, we can predict the expected utilization rate at the end of the first $(k=1)$ month using formula (7):

$$
U_{t+\tau}\left(U_{t}\right)
$$

Additionally, we calculate the expected utilization rate at the end of the second $(k=2)$ month by the formula taking into account the new input value of the utilization rate $U_{t+\tau}$, i.e.:

$$
U_{t+2 \tau}=U_{t+2 \tau}\left(U_{t+\tau}\right)
$$

Then, we repeat this procedure for the expected utilization rate at the end of each $k^{\text {th }}$ month with the formula:

$$
U_{t+k \times \tau}=U_{t+k \times \tau}\left(U_{t+(k-1) \times \tau}\right) \text {, }
$$

and so on until we cover the entire explored period $T=K \times \tau$.

In order to predict the expected drawn amount (EDA), the inverted formula should be used (3):

$$
E D A_{k} \equiv B_{t+k \times \tau}=U_{t+k \times \tau} \times L .
$$

Unfortunately, the author had available only a relatively short daily time series of the utilization rate for revolving corporate credit lines for one Ukrainian bank denominated in UAH. The data contains information for drawn and undrawn amounts on credit lines over 294 working days.

The calculated utilization rates $U_{t}$ are in a range from 0.5786 to 0.8558 . The current utilization rates $U_{t}$ have:

- a mean of $\mu_{U t}=0.7776$ and

- a standard deviation of $\sigma_{U t}=0.0547$.

We also calculate the statistical parameters for the utilization rates $U_{t+\tau}$ shifted ahead by $\tau=20$ working days:

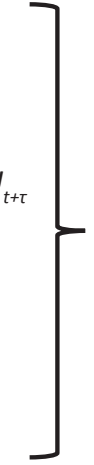

- $\mu_{U t+\tau}=0.7805$;

- $\sigma_{U t+\tau}=0.0508$;

- correlation coefficient $\rho=0.5907$ between $U_{t}$ and $U_{t+\tau}$.

As we have a relative short time series, then we assume, to illustrate the proposed approach, that the joint distribution of $U_{t}$ and $U_{t+\tau}$ are governed by a truncated bivariate normal distribution (Wilhelm and Manjunath, 2010) with parameters (A): 


$$
f\left(U_{t}, U_{t+\tau}\right)=\frac{\exp \left(-\frac{Q\left(U_{t}, U_{t+\tau}\right)}{2 \times\left(1-\rho^{2}\right)}\right)}{\int_{0}^{1} \int_{0}^{1} \exp \left(-\frac{Q\left(U_{t}, U_{t+\tau}\right)}{2 \times\left(1-\rho^{2}\right)}\right) d x d y},
$$

where

$$
Q\left(U_{t}, U_{t+\tau}\right)=\left(\frac{U_{t}-\mu_{U_{t}}}{\sigma_{U_{t}}}\right)^{2}-2 \times \rho \times\left(\frac{U_{t}-\mu_{U_{t}}}{\sigma_{U_{t}}}\right) \times\left(\frac{U_{t+\tau}-\mu_{U_{t+\tau}}}{\sigma_{U_{t+\tau}}}\right)+\left(\frac{U_{t+\tau}-\mu_{U_{t+\tau}}}{\sigma_{U_{t+\tau}}}\right)^{2}
$$

By substituting (13) into (7), we predict the conditional expected utilization rate by the following formula:

$$
U_{t+\tau}\left(U_{t}\right)=\frac{\int_{U_{t}}^{1} U_{t+\tau} \times \exp \left(-\frac{Q\left(U_{t}, U_{t+\tau}\right)}{2 \times\left(1-\rho^{2}\right)}\right) \times d U_{t+\tau}}{\int_{U_{t}}^{1} \exp \left(-\frac{Q\left(U_{t}, U_{t+\tau}\right)}{2 \times\left(1-\rho^{2}\right)}\right) \times d U_{t+\tau}}
$$

Some results of the estimation are presented in Figure 2-3. The calculations were conducted using MathCAD.

Figure 2. The dependences of future utilization rates on current utilization rates

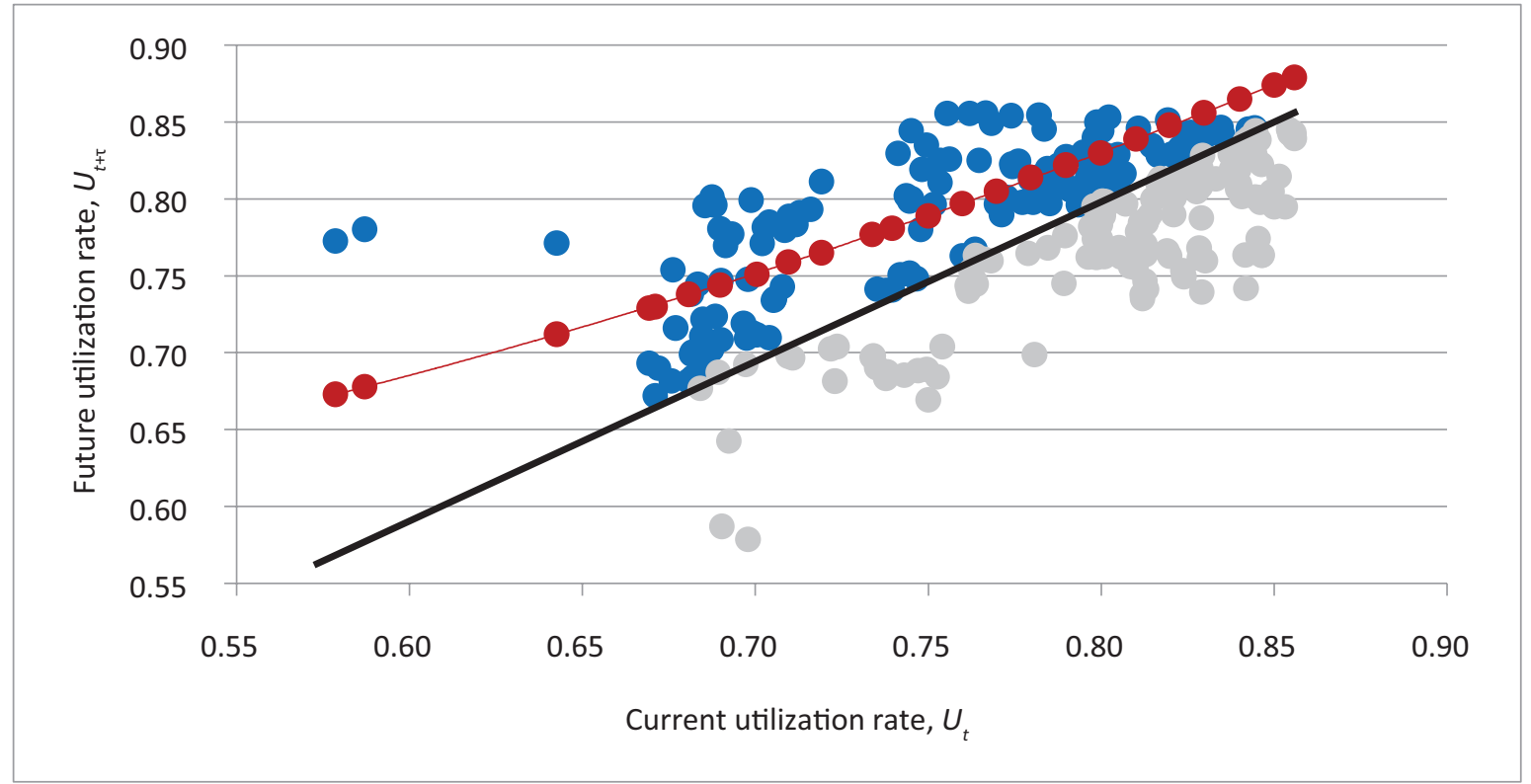

Blue points - actual $U_{t+\tau}>U_{t^{\prime}}$ grey points - actual $U_{t+\tau} \leq U_{t^{\prime}}$ black line $-U_{t+\tau}=U_{t^{\prime}}$ red points - the conditional expected utilization rate $U_{t+\tau}>U_{t^{*}}$

Developed by the author.

Under the assumption that variables $U_{t}$ and $U_{t+\tau}$ are governed by a bivariate normal distribution, the dependence of expected utilization rates on current utilization rates is non-linear (Figure 2) and has an admissible value of $R^{2}=0.57$.

Expressing the formula (2) for the liquidity conversion factor (LCF) in the next equivalent form:

$$
L C F_{k}=\frac{E D A_{k}-B_{t}}{L-B_{t}} \equiv \frac{E D A_{k} / L-B_{t} / L}{1-B_{t} / L}=\frac{U_{t+k \times \tau}-U_{t}}{1-U_{t}} .
$$


The dependences of the expected and actual monthly liquidity conversion factors $L C F$ on the current utilization rate $U_{t}$ are shown in Figure 3.

Figure 3. The dependences of expected and actual monthly liquidity conversion factors LCF on the current utilization rate $U_{t}$

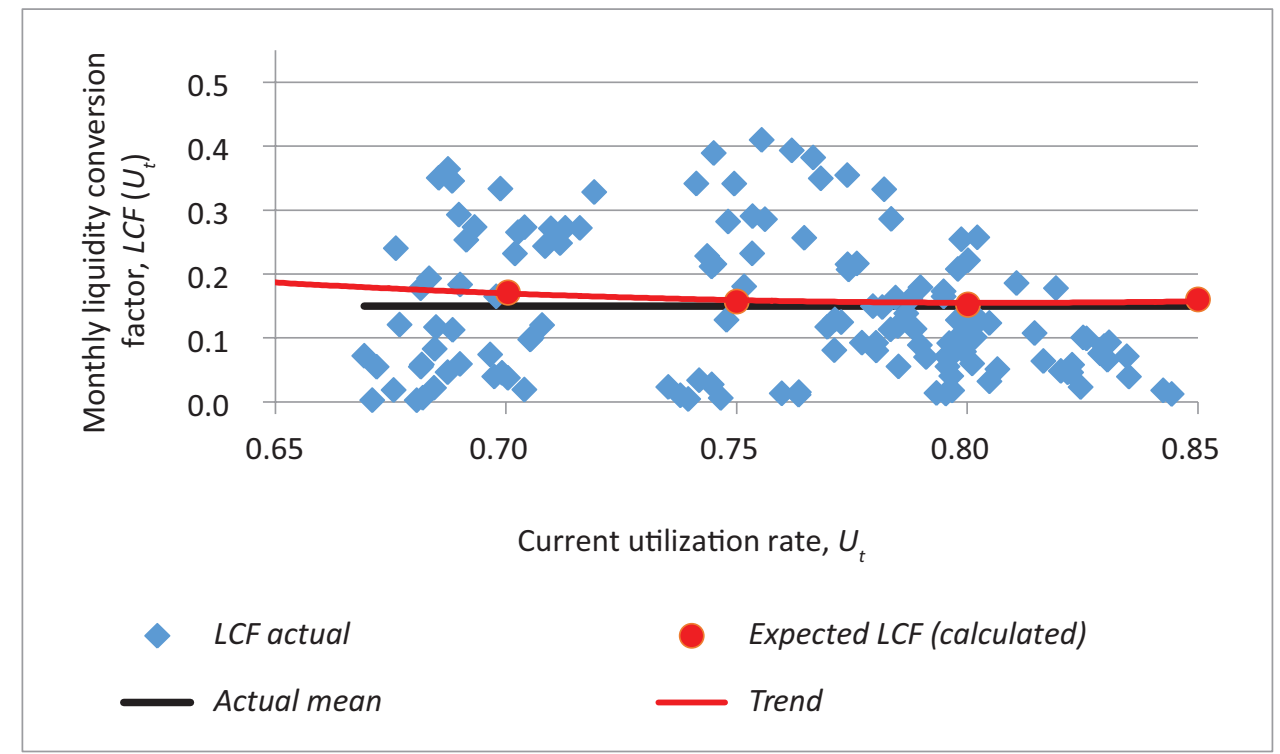

Developed by the author.

As shown in Figure 4, the expected monthly liquidity conversion factor LCF calculated using the proposed approach are well-matched with the actual mean of the LCF of $15 \%$. This value is higher than the $10 \%$ recommended by Basel (BIS, 2013). The example of estimating the expected utilization rate using the recursive procedure (8-11) is shown in Figure 4 and in Table.

Figure 4. Change in the expected utilization rate over time from point $U_{t}=0.7$

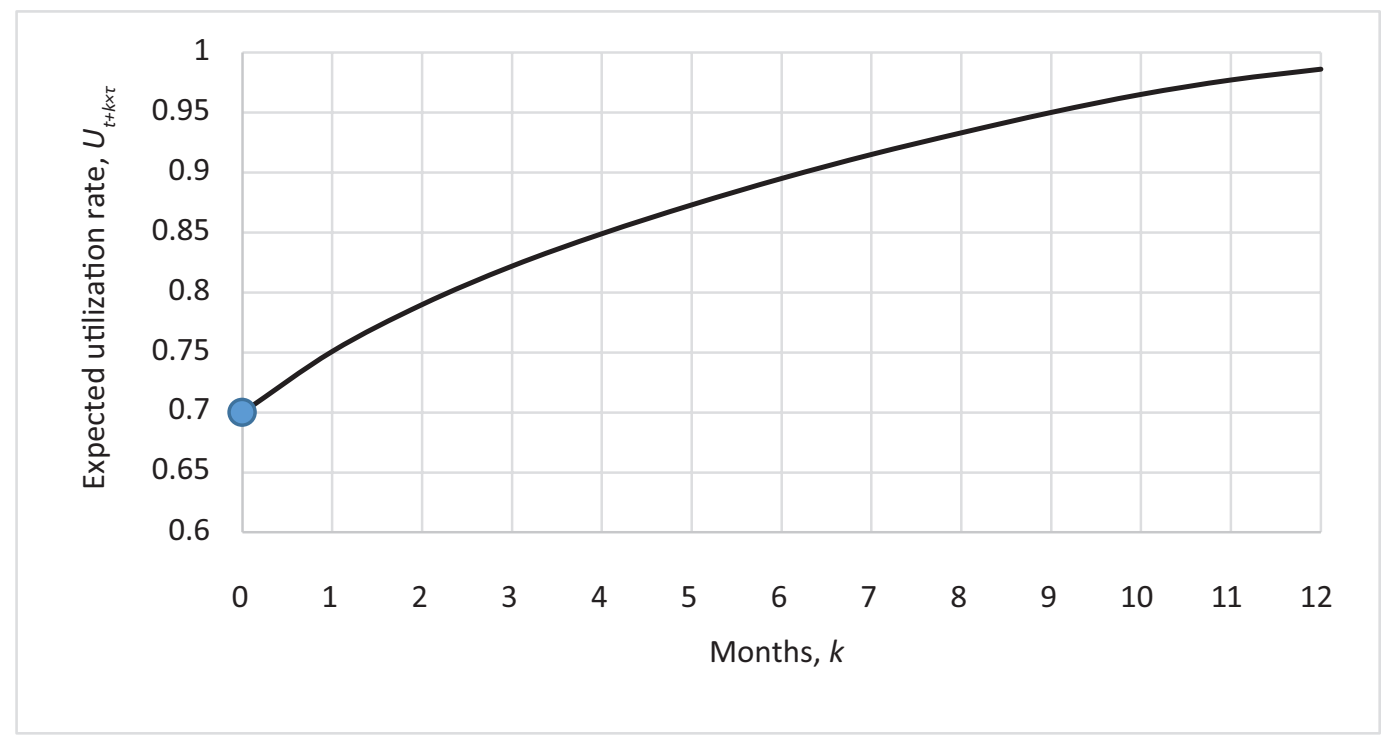

Developed by the author. 
Table. Change in the expected utilization rate over time from point $U_{t}=0.7$

\begin{tabular}{|l|c|c|c|c|c|c|c|c|c|c|c|c|c|c|}
\hline Month, $\boldsymbol{k}$ & 0 & 1 & 2 & 3 & 4 & 5 & 6 & 7 & 8 & 9 & 10 & 11 & 12 \\
\hline$U_{t+k \times \tau}$ & 0.7 & 0.751 & 0.79 & 0.822 & 0.849 & 0.873 & 0.895 & 0.915 & 0.933 & 0.95 & 0.977 & 0.977 & 0.986 \\
\hline
\end{tabular}

Developed by the author.

As shown in Figure 4, the utilization rate of corporate credit lines approaches a value of 1 at the end of the 12-month period. Accordingly, the LCF over the 12 months will be equal to:

$$
L C F_{12}=\frac{0.986-0.7}{1-0.7}=0.953
$$

In order to calculate Exposure At Default $(E A D)$, one should remember that the exposure of credit facilities is variable and dependent on the time of default. Therefore, the Exposure At Default, for instance, over 12 months is calculated by the following formula (Tong at al., 2016):

$$
E A D_{12}=\sum_{k=1}^{12} \frac{S_{k-1}-S_{k}}{1-S_{12}} \times E D A_{k}
$$

where $S_{k}$ is the survival function at month $k^{\text {th }}$ and $\left(S_{k-1}-S_{k}\right)$ gives the probability of default occurring in the $k^{\text {th }}$ month. Note that under IFRS 9, the $12^{\text {th }}$ month period may be lengthened for the loan's lifetime for certain impaired loans. We express the survival function $S_{k}$ through the default probability $p d$ within a month, assuming the default probability does not depend on time, by the well-known relation:

$$
S_{k}=(1-p d)^{k}
$$

Taking into account (17), we re-write formula (16) in the following form:

$$
E A D_{12} / L=\sum_{k=1}^{12} \frac{p d \times(1-p d)^{k-1}}{1-(1-p d)^{12}} \times U_{t+k \times \tau}
$$

Then, the credit conversion factor CCF over 12 months is derived from $E A D_{12}$ and calculated by the following equation (1):

$$
C C F_{12}=\frac{E A D_{12}-B_{t}}{L-B_{t}} \equiv \frac{E A D_{12} / L-B_{t} / L}{1-B_{t} / L}=\frac{E A D_{12} / L-U_{t}}{1-U_{t}}
$$

Consider the following example. Let the monthly expected default probability equal $p d=0.008$. Taking into account the change in the expected utilization rate (Table), we obtain the ratio of exposure to default to credit limit by the formula (18):

$$
E A D_{12} / \mathrm{L}=0.89 \text {. }
$$

And finally, the credit conversion factor over 12 months defined by the formula (19) will be:

$$
C C F_{12}=\frac{0.89-0.7}{1-0.7}=0.63
$$

Note that the value of the CCF is less than the value of the LCF (0.63 compared with 0.953$)$ as the drawn amount is decreased due to defaults. Note that the developed approach is suitable not only to estimate the expected loan losses for allowances and liquidity needs but for capital requirements as well.

\section{CONCLUSION}

This study proposes an alternate approach to predicting the drawn amount on committed credit facilities based on the target variable as the utilization rate and a truncated bivariate normal distribution. The method is simple to use and requires only five parameters: the means and standard deviations for the current and future utilization rates and the correlation coefficient between them. A comparison of the calculated expected and actual utilization rates shows sufficient accuracy for use in practice $\left(R^{2}=0.57\right)$. Obtained in this way, the expected utilization rate can be easily used to estimate the liquidity conversion factor (LCF) for the liquidity coverage ratio, the exposure at default (EAD), and the credit conversion factor (CCF). 
This approach is suitable for estimating liquidity needs and credit losses for provisioning as well as capital requirements. In our opinion, the approach has great potential for further development as it may include several explanatory variables by using a multivariate distribution. Moreover, there are great prospects in using a non-stationary distribution.

Further investigation can be focused on predicting Exposure At Default of so-called "indexed" banking products, such as domestic currency loans with an embedded option on its revaluation based on changes in a foreign exchange rate or other indexes which are becoming popular among Ukrainian banks. The exposures of these products may significantly increase at the time of default, which would pose additional risks to banks. The developed approach also requires testing for other products such as credit card and corporate overdraft facilities.

\section{References}

- BIS (2001). Basel Committee on Banking Supervision. The Standardised Approach to Credit Risk. Supporting Document to the New Basel Capital Accord. Available at: http://www.bis.org/publ/bcbsca04.pdf

- BIS (2013). Basel Committee on Banking Supervision. Basel III: The Liquidity Coverage Ratio and liquidity risk monitoring tools. Available at: http://www.bis.org/publ/bcbs238.pdf

- GPPC (2016). Global Public Policy Committee of representatives of the six largest accounting networks. The implementation of IFRS 9 impairment requirements by banks. Considerations for those charged with governance of systemically important banks. Available at: https://assets.kpmg.com/content/dam/kpmg/pdf/2016/06/gppc-ifrs9-implementation-considerations-20160617.pdf

- IFRS 9 Financial Instruments (replacement of IAS 39). Available at: http://www.ifrs.org/Current-Projects/IASB-Projects/Financial-Instruments-A-Replacement-of-IAS-39-Financial-Instruments-Recognition/Pages/Financial-Instruments-Replacementof-IAS-39.aspx

- Jacobs M. (2009). An Empirical Study of Exposure at Default. Risk Analysis, Division / Credit Risk Modelling Moody's KMV Credit Practitioner's Conference. September 9, 2009. Available at: https://papers.ssrn.com/sol3/Papers.cfm?abstract_ id $=1149407$

- Kim H., DeVaney S.A. (2001). The Determinants of Outstanding Balances among Credit Card Revolvers. Association for Financial Counseling and Planning Education. Available at: https://afcpe.org/assets/pdf/vol1216.pdf

- Korn G.A., Korn T.M. (1968). Mathematical Handbook for Scientists and Engineers. Definitions, Theorems, and Formulas for Reference and Review. Dover Publications, Inc. Mineola, New York.

- Moral G., de Espa-a B. (2006). EAD Estimates for Facilities with Explicit Limits. Available at: https://link.springer.com/chapter/10.1007/978-3-642-16114-8_11/fulltext.html

- National Bank of Ukraine (2016). Resolution No. 351. Regulation for Measuring Credit Risk Generated by Banks' Asset Operations. Available at: https://bank.gov.ua/document/download?docld=33378802

- Osipenko D., Crook J. (2015). The Comparative Analysis of Predictive Models for Credit Limit Utilization Rate with SAS/STAT. Paper No. 3328-2015. Available at: https://support.sas.com/resources/papers/proceedings15/3328-2015.pdf

- Regulation EU No. 575-2013 (2013). The European Parliament and the Council on Prudential Requirements for Credit Institutions and Investment Firms and Amending Regulation (EU) No. 648-2012. Available at: http://eur-lex.europa.eu/legalcontent/EN/TXT/?uri=celex\%3A32013R0575

- Taplin R., To H.M., Hee J. (2007). Modeling exposure at default, credit conversion factors, and the Basel II Accord. Journal of Credit Risk, Vol. 3, No. 2, pp. 75-84. https://doi.org/10.21314/JCR.2007.064

- Tong E.N.C., Mues C., Brown I., Thomas L.C. (2016). Exposure at Default Models with and without the Credit Conversion Factor. European Journal of Operational Research, Vol. 252, No. 3, pp. 910-920. https://doi.org/10.1016/j.ejor.2016.01.054

- Wilhelm S.,Manjunath B.G. (2010). Tmvtnorm: A Package for the Truncated Multivariate Normal Distribution. Contributed Research Articles. The R Journal, Vol. 2/1, June 2010. pp. 25-29. Available at: https://journal.r-project.org/archive/2010/RJ2010-005/RJ-2010-005.pdf

- Yang B.H., Tkachenko M. (2012). Modeling of EAD and LGD: Empirical Approaches and Technical Implementation. Available at: https://mpra.ub.uni-muenchen.de/57298/1/MPRA_paper_57298.pdf 


\title{
FISCAL POLICY REACTION FUNCTION AND THE SUSTAINABILITY OF FISCAL POLICY IN UKRAINE
}

\author{
Artem Vdovychenko \\ National Bank of Ukraine \\ Email: artem.vdovychenko@bank.gov.ua
}

\section{ABSTRACT}

This study analyzes the fiscal policy reaction function with switching regimes. We use Logistic Smooth Transition Regressions (LSTR) to show that fiscal policy in Ukraine during the study period remained largely in passive mode, switching to active mode during periods of a high output gap and elevated debt-to-GDP ratio. An important finding is that the fiscal policy reaction function is nonlinear. Specifically, the response of fiscal policy to the output gap is asymmetric: fiscal policy is pro-cyclical during periods of economic growth but neutral in recession.

\section{JEL Codes: E62, H62, H63}

\section{Keywords: fiscal policy, fiscal sustainability, active/passive fiscal policy, regime switching}

\section{INTRODUCTION}

The response by fiscal policy to changes in the macroeconomic environment or the statistical evaluation of fiscal rules is a theme that is discussed intensively in academic circles. A promising topic for discussion is the nonlinearity of the fiscal policy reaction function (FPRF) and switching of fiscal policy regimes. However, economists have mainly focused on fiscal policy in advanced economies or small open economies with developed democracies. Emerging markets have some inherent features like high pro-cyclicality and low sustainable debt limits, per the findings of Mendoza and Ostry (2007), but they remain largely unexamined. Ukraine is a small open economy that has experienced exponential debt growth over the last ten years and therefore represents an interesting case for testing the fiscal policy reaction function.

From a policy perspective, this study aims to identify the causes of the exponential growth in public debt in Ukraine based on the evolution of fiscal policy approaches. We estimate the FPRF for Ukraine from quarterly data, like Burger and Marinkov (2012), and analyze fiscal policy regimes using regressions with breaks in time series and splines for the level of public debt and the phase of the business cycle. We then use an approach similar to Legrenzi and Milas (2013) to estimate LSTR models with output gaps and debt ratios in the role of transition variables to better understand the causes of switching between fiscal policy regimes.

The paper is structured as follows: the second section reviews the literature on the relationship between the concept of fiscal sustainability and the fit of the FPRF and provides an overview of fiscal policy regimes in emerging markets; the third section describes the methods we prefer for estimating the FPRF given Ukraine's switching regimes; in the fourth section we describe the dataset; in the fifth section, we present the results of the estimates; the last section outlines a summary of the findings and implications for fiscal policy.

\section{LITERATURE REVIEW}

Fiscal policy targets have long been the topic of discussion. Based on existing theory and standard assumptions, researchers argue that the objective of fiscal policy is to regulate the cyclical fluctuations of an economy or to maintain fiscal sustainability. The FPRFs are designed to determine the achievement of fiscal policy goals in different countries or in different time periods. The fit of the FPRF itself can be quite different, but it must include an indicator of public debt and the position of the economic cycle (output gap). The coefficient of the public debt variable is a primary interest because, along with the co-integration of fiscal variables, a statistically significant positive reaction of the primary deficit on changes in the level of debt is a sign of sustainable fiscal policy (Bohn, 1998). A positive debt level coefficient in the FPRF means a government reduces the budget deficit in response to debt growth and increases the deficit when debt decreases. By reviewing the empirical literature that analyzes the FPRFs, we see there are conventional modifications used by researchers to better describe the behavior of fiscal indicators. De Mello (2005) represents the general equation of the FPRF as follows: 


$$
b_{i, t}=a_{0}+a_{1} b_{i, t-1}+a_{2} d_{i, t-1}+a_{3} C_{i, t}+u_{i t}
$$

where $b_{i, t}$ is the ratio of the primary budget balance to nominal GDP; $b_{i, t}$ is the ratio of public debt to nominal GDP; and $C_{i, t}$ is a set of control variables for the different levels of budgets $i$ in time period $t$. To determine the control variables, de Mello (2005) used the following intertemporal budget constraint:

$$
b_{t}+\left(r_{t}-g_{t}\right) d_{t-1}=\Delta d_{t}+\Delta m_{t}+\left(\pi_{t}+g_{t}\right) m_{t-1}
$$

where $\pi_{t}$ represents inflation; $m_{t}$ is the ratio of the monetary base to GDP; and $g_{t}$ is the real GDP growth rate. Using this relationship, the author shows that cyclical output and inflation should be included as control variables in equation (2) to account for revenues from seigniorage.

In some studies, the authors try to account for the nature of small open economies by including specific variables in the FPRF. Penalver and Thwaites (2006) assumed that public debt consists of foreign and domestic debt and, consequently, the debt cost and the dynamics of these components will be influenced by variables like the real exchange rate and foreign and domestic interest rates. The authors concluded that the uncertainty of macroeconomic forecasts and the response of variables like the public debt-to-GDP ratio and interest rates significantly strengthen the reaction of fiscal policy to changes in public debt.

Another common practice is the inclusion of dummies to extract fiscal policy features that were a characteristic for a given political regime in the FPRF (Burger and Marinkov, 2012). In some studies, economists analyze fiscal policy reactions not in the form of the response of the total primary deficit, but as the response of specific components of income and expenditure (Claeys, 2008). These studies allow conclusions to be made concerning the exact budget components that adjust the overall budget balance in response to fluctuations in the level of debt and macroeconomic indicators.

Changes or switches to the fiscal policy approach complicates FPRF estimates because the simple linear model reflects the averaged coefficients of the different approaches. In the literature, the solution to this problem was found in the use of models with switching regimes. Fiscal policy regimes can be introduced into the models exogenously or endogenously. The introduction of exogenous regimes occurs when a researcher has an a priori notion of the period in which the properties of fiscal policy could change. Technically, this is done by evaluating the FPRF for different time periods (Gali and Perotti, 2003) or by introducing dummy variables to, for example, exclude specific political events (Burger and Marinkov, 2012). Another approach is to identify regime-switching based on endogenous information when under the influence of a transition variable, the FPRF coefficients change, and these changes are estimated based on the information contained in the data itself. Legrenzi and Milas (2013) used a Smooth Transition Regression (STR) to estimate the simple FPRF, which assumed a switch between the coefficients of the business cycle and the short-run relationship between the primary budget deficit and public debt. In this study, transition variables include the level of public debt in the previous year, the business cycle stage in the previous year, and the difference between the level of public debt and the state-varying threshold, based on an index of financial pressure. The results show that the countries studied (Greece, Ireland, Portugal, and Spain) have had sustainable fiscal policies from the 1960 s to the present. At the same time, during periods of increasing financial pressure, these countries reduced marginal debt levels and thereafter corrected debt levels to re-establish fiscal sustainability. Along with other approaches, Burger et al. (2011) use a Threshold Autoregressive model (TAR), where the output gap serves as a transition variable and the threshold is set at zero. Thus, fiscal policy becomes counter-cyclical during periods of recession. Favero and Monacelli (2005), Claeys (2008), Burger and Marinkov (2012) use regressions with Markov switching regimes where the regimes are determined endogenously. Burger and Marinkov (2012) use this approach to reflect the shift of fiscal policy from passive to active and vice versa in South Africa. Claeys (2008) used this approach to analyze the characteristics of fiscal policy in different regimes. The author also investigated the reaction of different budget expenditure and income components. Favero and Monacelli (2005), in addition to the identification of fiscal policy regimes in the US, also studied their synchronization with monetary policy regimes, in doing so enriching the analysis of macroeconomic conditions of government and central bank actions.

The FPRF is also useful in characterizing fiscal policy as active or passive. This classification is slightly different than the counter-/pro-cyclical or sustainable/unsustainable fiscal policy characterization as both coefficients (debt and output gap) must be switched in the FPRF. Under this classification, active fiscal policy comprises fiscal actions not related to changes in public debt, i.e. through fiscal instruments used by the government to influence other macroeconomic parameters like level of output, employment, etc. (Leeper, 1991). Passive policy includes actions that are limited by public debt levels and intertemporal budget considerations. In this type of regime, the main objective of fiscal policy is to maintain or achieve a sustainable level of public debt. In the empirical context, this means that in the case of passive fiscal policy, the coefficient of public debt is positive and statistically significant. Alternately, a statistically significant coefficient on other control variables, especially the output gap, is a sign of an active fiscal policy.

There are numerous published works on the sustainability of fiscal policy for different categories of countries. In general, the conclusion is that on average, fiscal policy in emerging market countries responds to the parameters of sustainability. Abiad and Ostry (2005) emphasized that along with the general sustainability of fiscal policy, exceeding the threshold levels for debt diminishes the responsiveness to debt for emerging market countries. This speaks to the nonlinearity of the reaction of 
fiscal policy depending on the economic conditions. The authors argue that there are two types of fiscal policy in developing countries. They state that the ability of policymakers to maintain fiscal solvency through higher primary balances appears to decrease in countries with mean and median debt ratios above $50-60 \%$.

Mendoza and Ostry (2008) studied fiscal solvency in industrialized countries, emerging markets, and countries with high and low debt levels. They concluded the fiscal sustainability criteria are satisfied in general by all groups of countries, however, a government's ability to meet the criteria of fiscal sustainability greatly reduces as debt levels rise. In contrast to existing literature, they did not find that the responsiveness to debt increases when debt exceeds threshold levels in panel regressions for advanced countries, but it does diminish for emerging market countries.

Ghosh et al. (2013) examined the phenomenon of "fiscal fatigue", referring to the switching of fiscal policy in an unsustainable regime in response to a high debt ratio. In the sample of developed countries, the authors empirically proved the existence of "fiscal fatigue" by constructing a cubic FRFP. This is a specific modification of the model with three fiscal policy regimes. The authors show that at low debt levels, the relationship between budget deficits and debt levels is not significant or even negative. As debt increases, the responsiveness of fiscal policy also increases. However, at high debt levels, that reaction begins to weaken and then decreases at extremely high debt levels. Estimates suggest the responsiveness of fiscal policy to debt levels starts to decrease at $90-100 \%$ of GDP and becomes negative when debt levels approach $150 \%$ of GDP. This conclusion contradicts Bohn's findings (1998) for the US, that the fiscal reaction increases as debt increases. The authors explain the phenomenon of "fiscal fatigue" by the government's inability to increase primary balances at the same pace as the pace of debt growth.

Another facet of fiscal policy is its reaction to fluctuations in GDP. The response of fiscal policy to a business cycle is a wellresearched topic. In general, the work has found that in emerging markets, fiscal policy is pro-cyclical or neutral. An important issue in the context of fiscal sustainability is the symmetry of the fiscal policy response to different phases of the economic cycle. In April 2015, the IMF reported that symmetry in the fiscal response in good and bad times is important for three main reasons: to rebuild buffers ahead of the next cyclical downturn, to reduce the risk of overheating, and to avoid growth in public debt in successive cycles. According to the report, emerging markets are asymmetrical in their fiscal policy response to economic cycles. In periods of recession, fiscal policy tends to be counter-cyclical, while during periods of economic growth, policy is pro-cyclical. The IMF showed that a systematic asymmetric response is associated with a non-negligible increase in the debt-to-GDP ratio. Under benign macroeconomic assumptions, asymmetric stabilization could, after 20 years, result in a debt-to-GDP ratio much higher than with symmetric stabilization.

In terms of switching between passive and active fiscal policy approaches, the asymmetry of the fiscal response to business cycle phases could carry a hidden threat to debt levels. If the government pursues a passive fiscal policy (pro-cyclical and sustainable) during periods of a positive output gap, this will result in an increased budget deficit and a decreased debt ratio. This approach will contribute to an overheating of the economy and create the conditions for an increase in debt and a narrowing of fiscal space in subsequent periods. This type of policy approach cannot be considered prudent. Those conditions are better suited to an active fiscal policy, which can cool down an economy during a growth phase and contribute to an increase of fiscal resources for counter-cyclical action in future economic downturns. In this study, we show that passive fiscal policy during economic booms in Ukraine has led to the uncontrolled growth of public debt.

\section{THE METHOD}

To estimate the FPRF for Ukraine, we start with the standard formula:

$$
\operatorname{prsurpl}_{t}=a_{0}+a_{1} \operatorname{prsurpl}_{t-4}+a_{2} \mathrm{debt}_{t-4}+a_{3} \text { gap }_{t-4}+a_{4} \text { pol }_{t}+\sum_{\mathrm{j}=1}^{\mathrm{n}} b_{j} D_{j}+u_{t^{\prime}}
$$

where prsurpl is the ratio of the primary budget deficit to GDP; debt is the ratio of total government and guaranteed debt to GDP; gap is the cyclical deviation of nominal GDP from potential GDP; pol is a political dummy, representing the two quarters prior to presidential or parliamentary elections; and $D$ is a dummy to control for data outliers. To estimate the function, we use quarterly data, which forces us to enter a four-quarter lag for the explanatory variables to the formula. It is more natural to study the reaction of fiscal policy using annual data, since the budget is adopted annually and the government often reacts to economic changes in the subsequent year. However, using annual data would reduce the number of observations for Ukraine, since the calculations cover the years 1998-2015. Moreover, quarterly data are more appropriate for identifying specific fiscal policy regimes. Using the practice of Burger and Marinkov (2012), we use quarterly data with a fourth lag as a substitute for annual data with one lag. In studies with fiscal rules estimates, quarterly data are often used when explaining the variables included in the model without lags. That leads mainly to an estimate of the automatic reaction of fiscal parameters to economic conditions. At the same time, the discretionary reaction is largely ignored because the time required to implement fiscal decisions will not allow them to be executed within one quarter. We therefore note that our use of variables with a four-quarter lag highlights the discretionary government response. The model (3) is estimated using Ordinary Least Squares (OLS), Generalized Method of Moments (GMM), and Limited Information Maximum Likelihood (LIML). The use of lags in the explanatory variables reduces endogeneity risk, but the model also includes a lag for the dependent variable, which retains 
the probability of endogeneity and bias of all coefficients. We treated prsurpl, debt, and gap as endogenous variables and used variables that reflect external economic conditions as instruments. In particular, we used variables that reflect the state of the global economy (the average growth rate for OECD countries), the state of global commodity markets that influence the Ukrainian economy (agricultural raw materials index, metals price index, non-fuel price index, sunflower oil price, wheat price index, fertilizers price index), and the real effective exchange rate as an indicator of relative prices between Ukraine and its major trading partners. Those variables are used because Ukraine's economy is small and open, meaning Ukraine is a pricetaker on international commodity markets. Therefore, international economic trends are weakly dependent on the events and political decisions in Ukraine (exogeneity), but they strongly influence the economic situation in Ukraine itself (thus they should be strong instruments).

Given the growing literature on political business cycles, we also include in the FPRF a political variable. On the belief that fiscal manipulations by incumbent politicians during pre-election periods help explain changes in budget parameters, their inclusion in the model should improve the efficiency of estimates.

Since we assume the FRFP is nonlinear, we test the presence of structural breaks in the model's (3) coefficients. Significant changes in the business cycle and debt coefficients would signal changes to fiscal policy in Ukraine.

To determine fiscal regimes depending on the phase of the economic cycle and debt levels, we run a set of models with splines, which distinguish the coefficients of the FPFF depending on the data being above or below the spline. For the splines, we used the zero level of the business cycle (when the GDP gap is equal to zero), a sample mean of the debt ratio, and positive/ negative changes in public debt.

Determining the splines exogenously is subjective, which can result in an incomplete understanding of the process of fiscal policy regime-switching. To identify switching thresholds based on the statistical results, we applied a Logistic Smooth Transition Regression (LSTR) in the following form:

$$
\operatorname{prsurpl}_{t}=\phi^{\prime} \mathbf{x}_{t}+\theta^{\prime} \mathbf{x}_{t} G\left(\gamma, c, s_{t-n}\right)+u_{t^{\prime}} \quad t=1, \ldots, T,
$$

where $\mathbf{x}_{t}$ is the vector of the exogenous explanatory variables; $\phi=\left(\phi_{0}, \phi_{1}, \ldots, \phi_{m}\right)^{\prime}$ and $\theta=\left(\theta_{0}, \theta_{1}, \ldots, \theta_{m}\right)^{\prime}$ are parameter vectors of size $((m+1) \times 1), u_{t} \sim$ i.i.d. $\left(0, \sigma^{2}\right)$. For that type of model, we assumed the following transition function:

$$
G\left(\gamma, c, s_{t-n}\right)=\left(1+\exp \left\{-\gamma \prod_{k=1}^{K}\left(s_{t-n}-c_{k}\right)\right\}\right)_{-1}, \gamma>0,
$$

where $S_{t-n}$ is a transition variable, which in our study is used with a lag $\mathrm{n} ; c_{k}$ is a location parameter from vector $\mathrm{c}=\left(\mathrm{c}_{1}, \ldots, C_{K}\right){ }^{\prime}$ with restrictions $\mathrm{c}_{1} \leq \ldots \leq c_{K}$; and $\gamma$ is the slope. In our approach:

- The same variables as in the model (3) were used as exogenous variables;

-We assumed the coefficients of the public debt ratio and the output gap will switch between fiscal policy regimes;

- Fiscal policy switches regimes depending on the magnitude of the transition variable $\left(s_{t-n}\right)$ relative to the variable $s_{\mathrm{k}^{\prime}}$ which is the switching threshold;

- A regime is weighted using the $\theta_{m}$ coefficient, and $\gamma>0$ defines the smoothness of the transition between regimes.

This type of model and the construction of it are described in Teräsvirta (2004), while Legrenzi and Milas (2013) established the notion of this type of FPRF specification. In this study, unlike in previous works, we test the LSTR model for the size of vector $c=\left(c_{1}, \ldots, c_{K}\right)^{\prime}$. The most common cases are regressions with $K=1$ and $K=2$. In the case of $K=1$, the model parameters vary monotonically based on the functional relation with $s_{t-n}$ until policy switches to another regime. These models describe the asymmetric behavior of variables at high and low values of the transition variable. The transition between regimes can be smooth. The LSTR model with $K=2$ (LSTR2) assumes that the coefficients vary symmetrically around the point $\left(c_{1}+c_{2}\right) / 2$, which is within the range of the transition variable. These models are used when the variables behave in the same manner at high and low magnitudes of $s_{t-n}$, but switch to another regime while $s_{t-n}$ is intermediate.

The LSTR2 regression is a three-regime model, two of which are symmetrical. The work of Ghosh et al. (2013) serves as evidence for the possibility of the existence of this type of nonlinearity in fiscal policy. The authors, while using a cubic regression empirically, show that fiscal policy becomes less responsive to debt at extremely low and high debt levels, but reacts to increasing debt at moderate debt levels.

Before building a model, researchers should run a series of tests for nonlinearity in relationships caused by the transition variables. As transition variables, we test the ratio of total public debt to GDP and the output gap. Variables with lags ranging from $t-4$ to $t-8$ were tested. These potential transition variables were chosen based on the assumption that a change of fiscal policy to another regime is caused by the phase of the economic cycle and the overall level of public debt. 
The lags for the transition variables are chosen based on the assumption that the government determines the parameters of the following year's budget based on the previous year's information on public debt and the stability of the financial system.

As an alternate variable to test the robustness of our results, we use the ratio of the cyclically adjusted primary deficit to potential GDP $(c a b)$, instead of the ratio of the primary deficit to GDP. The $c a b$ is an indicator that better identifies discretionary fiscal policy, thus allowing us to be confident the results are not biased by an automatic reaction.

\section{DATA}

We use quarterly data for 1998-2015, the maximum available period. Data on public debt is sourced from the Ministry of Finance's web-based database, budget data is taken from the website of the State Treasury of Ukraine, and macroeconomic data is sourced from the database of the National Bank of Ukraine (NBU). The prsurpl variable was seasonally adjusted to control for its high seasonality. Debt was estimated as the logarithmic of the ratio of total government and guaranteed debt to seasonally adjusted GDP1. Before estimating the output gap (gap) using the Hodrick-Prescott filter, nominal GDP was transformed into logarithms and seasonally adjusted. As a proxy for the cab, we used residuals from a regression of the form:

$$
P R_{D E F t}=c_{0}+c_{1} G D P_{\text {cyclet }}+e_{t},
$$

where $P R_{D E F t}$ is the seasonally adjusted primary deficit; $G D P_{\text {cycle }}$ is the seasonally adjusted GDP gap in absolute terms; and $e_{t}$ represents the residuals that do not include the automatic response of fiscal policy on cyclical fluctuations of GDP. Therefore, we assume that the automatic response of fiscal parameters presents itself during a quarter, while the government's discretionary actions have a lag of at least one quarter.

The time series we include in our model is stationary, which is important for the consistent estimation of parameters of the FPRF. The output gap is stationary by definition, but the unit root tests of public debt and primary deficit to GDP ratios typically produce mixed results. This is especially true for Ukraine, where public debt levels were distorted by a powerful structural shock in 2008, invalidating standard tests. However, Bohn (1998) and Bohn (2007) noted that these time series have considerable inertia, so determining their stationarity is challenging. Accordingly, stationarity should be based not on the statistical tests that lose their power in a relatively small sample and with the presence of structural breaks, but on economic logic. As shown in Table 1, ADF, KPSS, and Elliot-Rothenberg-Stock (ERS) Point optimal tests were conducted for the formal conclusions on the stationarity of time series. The order of lags in ADF was selected based on the AIC information criterion, all tests were conducted based on the assumption that intercept is stationary.

\section{Table 1. Results of stationarity testing for FPRF variables}

\begin{tabular}{|c|c|c|c|}
\hline \multirow{2}{*}{ Variable (period) } & $A D F(H 0: \rho=1)$ & KPSS (HO: $\rho \neq 1)$ & ERS (HO: $\rho=1)$ \\
\hline & t-statistics & LM-statistics & t-statistics \\
\hline prsurpl (1998q1-2015q4) & $-5.3(p<0.01)$ & $0.3(p=0.10)$ & $2.2(p<0.05)$ \\
\hline$c a b(1998 q 1-2015 q 4)$ & $-4.7(p<0.01)$ & $0.7(p<0.05)$ & $1.6(p<0.01)$ \\
\hline gap (1998q1-2015q4) & $-3.5(p<0.01)$ & $0.1(p>0.10)$ & $1.1(p<0.01)$ \\
\hline debt (1998q1-2015q4) & $-0.5(p>0.10)$ & $0.2(p>0.10)$ & $12.2(p>0.10)$ \\
\hline d_debt (1998q2-2015q4) & $-7.6(p<0.01)$ & $0.2(p>0.10)$ & $0.7(p<0.01)$ \\
\hline
\end{tabular}

The stationarity tests show that the cycles of GDP and the primary surplus, with very high probability, are stationary processes. At the same time, according to the ADF test, the cyclically adjusted budget balance and the first differences of the debt ratio are stationary, but confirm their stationary according to the KPSS test only at the level of approximately 5\%. For the final conclusions, the ERS test was conducted because of the disadvantages of the ADF and KPSS tests, namely that they are severely distorted by size and have difficulty in distinguishing highly persistent stationary processes from nonstationary processes.

\footnotetext{
${ }^{1}$ The level of public debt is the stock variable and quarterly GDP is the flow variable. As a result, on graphs and in tables, debt, which equals log (total government and guaranteed debt / seasonally adjusted GDP), yields high values. Taking the exponent and dividing this figure by 4 yields an approximation of the average yearly ratio of debt-to-GDP.
} 


\section{ESTIMATION RESULTS}

According to the proposed approach, we estimated the model of type (3) for the prsurpl and cab variables using OLS, GMM, and LIML. The results are presented in Table 2. A dummy variable (d_2010q03) represents the third quarter of 2010 when the government of Ukraine issued and sold approximately UAH 16.5 billion in VAT bonds, artificially increasing VAT revenues and distorting budgetary statistics. Along with the coefficients, the table contains statistics to judge the accuracy of standard errors estimation and bias. Note that when identifying problems with autocorrelation or the heteroskedasticity of errors, we applied the HAC variance-covariance matrix to mitigate the problems with standard errors. For the models with the instruments, we provide the statistics, characterizing the degree of the instruments' exogeneity and their explanatory power. The test results indicate that the selected instruments are exogenous, but may be weak. The underidentification test does not indicate a problem, but the $\mathrm{F}$ statistics in the Weak identification test indicates that the maximal IV bias relative to OLS could reach $20 \%$. For this reason, along with the GMM, we used LIML, which is less sensitive to the problems of weak instruments.

Table 2. The results of linear FPRF estimations for Ukraine, 1998-2015

\begin{tabular}{|c|c|c|c|c|c|c|}
\hline & \multicolumn{2}{|c|}{ OLS } & \multicolumn{2}{|c|}{ GMM } & \multicolumn{2}{|c|}{ LIML } \\
\hline & prsurpl & $c a b$ & prsurpl & $c a b$ & prsurpl & $c a b$ \\
\hline Constant & 0.01 & $0.01 * *$ & 0.01 & 0.01 & 0.01 & 0.01 \\
\hline d_2010q03 & $-0.08 * * *$ & $-0.08 * * *$ & $-0.06^{*}$ & $-0.08^{*}$ & $-0.06^{*}$ & $-0.09 * *$ \\
\hline $\operatorname{prsurpl}_{t-4}, c a b_{t-4}$ & $0.24 *$ & $0.38 * * *$ & $0.68^{* *}$ & $0.69 * * *$ & $0.74^{* *}$ & $0.88^{* * *}$ \\
\hline$g a p_{t-4}$ & -0.09 & -0.07 & $-0.19 * *$ & $-0.13^{*}$ & $-0.21 * * *$ & 0.01 \\
\hline$d_{-} d e b t_{t-4}$ & $0.04^{* *}$ & $0.04 *$ & 0.00 & 0.00 & 0.01 & 0.09 \\
\hline $\operatorname{pol}_{t}$ & $-0.01^{* * *}$ & $-0.01 * *$ & $-0.02^{* *}$ & $-0.02 *$ & $-0.02 * *$ & $-0.02 *$ \\
\hline Obs. & 67 & 67 & 61 & 61 & 61 & 61 \\
\hline Adj. R-squared & 0.27 & 0.29 & & & & \\
\hline Autocorrelation in residuals test & $p=0.03$ & $p=0.42$ & $p=0.19$ & $p=0.13$ & $p=0.17$ & $p=0.17$ \\
\hline Heteroscedasticity test & $p=0.42$ & $p=0.34$ & $p=0.26$ & $p=0.31$ & $p=0.35$ & $p=0.25$ \\
\hline Sargan statistics & & & $p=0.46$ & $p=0.61$ & $p=0.51$ & $p=0.34$ \\
\hline Endogeneity test & & & $p=0.00$ & $p=0.00$ & $p=0.00$ & $p=0.00$ \\
\hline Underidentification test & & & $p=0.01$ & $p=0.00$ & $p=0.01$ & $p=0.03$ \\
\hline Weak identification test & & & 5.86 & 6.76 & 5.86 & 3.74 \\
\hline
\end{tabular}

Note: $* * *$, and $* * *$ denote statistical significance at $10 \%, 5 \%$, and $1 \%$, respectively. Autocorrelation in the residuals test - Breusch-Godfrey Serial Correlation LM Test (4 lags) for OLS estimates and Cumby-Huizinga test for GMM and LIML. Heteroscedasticity test - Breusch-Pagan-Godfrey test for OLS estimates and Pagan-Hall general test for GMM and LIML. The Cragg-Donald Wald F and Kleibergen-Paap rk Wald F statistics (in case of heteroscedasticity or serial correlation) are used to test weak identification issue.

The results in Table 2 show that Ukraine's fiscal policy was in a passive state during the reported period. The OLS models indicate a positive and statistically significant response of the primary deficit and the cyclically adjusted primary deficit to public debt. Meanwhile, the output gap coefficients show the pro-cyclical nature of fiscal policy, although this lacks statistical significance. Judging by the signs of the coefficients, OLS and the methods of instrumental variables indicate identical characteristics for Ukraine's fiscal policy. The decrease of the statistical significance of the coefficients in the models estimated by GMM and LIML can be explained by the loss of efficiency inherent to those methods of estimation.

The linear FPRF in model (3) contains coefficients that are not stable. To show this, we conducted a series of tests for changes in regression coefficients that are caused by structural breaks in the data. The tests for the unknown dates of the structural breaks included coefficients of the variables in which we are most interested (Table 3). 


\section{Table 3. The results of the Wald test for structural breaks}

\begin{tabular}{|c|c|c|}
\hline Coefficients included in the test & Break date & Prob. $>\mathrm{chi}^{2}$ \\
\hline \multicolumn{3}{|c|}{ Dependent variable: $\operatorname{prsurp}_{t}$} \\
\hline$g a p_{t-4}, d_{-} d e b t_{t-4}$ & $2006 q 3$ & $p=0.03$ \\
\hline$g a p_{t-4^{\prime}}$ & $2006 q 3$ & $p=0.02$ \\
\hline$d_{-} d e b t_{t-4}$ & $2011 q 1$ & $p=0.08$ \\
\hline \multicolumn{3}{|c|}{ Dependent variable: $\mathrm{cab}_{t}$} \\
\hline$g a p_{t-4}, d_{-} d e b t_{t-4}$ & $2006 q 3$ & $p=0.56$ \\
\hline $\operatorname{gap}_{t-4^{\prime}}$ & $2006 q^{3}$ & $p=0.26$ \\
\hline$d_{-} d e b t_{t-4}$ & $2008 q 1$ & $p=0.47$ \\
\hline
\end{tabular}

The results in Table 3 allow us to make several conclusions. First, the structural breaks in the data, which lead to an instability of the coefficients, are better identified in a model of the primary surplus. Second, both the debt ratio and the output gap show changes in the coefficients, what enables us to identify 3Q 2006 as the common structural break date for these variables. Based on that date, we ran regressions of fit (3) using Least Squares with Breaks. When the model showed serial correlation and heteroskedasticity errors, we used the HAC matrix to estimate the standard errors. We also estimated the FPRF with a structural break in $4 Q 2008$, the start of the powerful downturn of the Ukrainian economy and of the financial sector. This crisis was notable for the rapid depreciation of the hryvnia, falling stock valuations, the explosion of CDS spreads on Ukrainian bonds, and the adoption of special fiscal programs in response to the debt crisis and the recession. Based on these events, the crisis in 4Q 2008 may mark a change in the direction of fiscal policy. ${ }^{2}$ Table 4 outlines the estimation results.

\section{Table 4. Least Squares with Breaks estimation of the FPRF}

\begin{tabular}{|c|c|c|c|c|}
\hline \multirow[t]{2}{*}{ Variables } & prsurpl & $c a b$ & prsurpl & $c a b$ \\
\hline & \multicolumn{2}{|c|}{$1999 q 2-2006 q 3$} & \multicolumn{2}{|c|}{$1999 q 2-2008 q 4$} \\
\hline$g a p_{t-4}$ & $0.15^{* *}$ & 0.12 & 0.54 & 0.01 \\
\hline \multirow[t]{2}{*}{$d_{-} d e b t_{t-4}$} & $0.03 * *$ & 0.02 & 0.01 & 0.01 \\
\hline & \multicolumn{2}{|c|}{$2006 q 4-2015 q 4$} & \multicolumn{2}{|c|}{$2009 q 1-2015 q 4$} \\
\hline$g a p_{t-4}$ & $-0.22 * *$ & $-0.10 * * *$ & $-0.20 * * *$ & $-0.10 * *$ \\
\hline \multirow[t]{2}{*}{$d_{-} d e b t_{t-4}$} & $0.03 * * *$ & $0.04 * * *$ & $0.04 * * *$ & $0.05^{* * *}$ \\
\hline & \multicolumn{4}{|c|}{ Non-Breaking Variables } \\
\hline Constant & $0.01 * *$ & $0.01 * *$ & 0.01 & $0.01 *$ \\
\hline d_2010q03 & $-0.09 * * *$ & $-0.09 * * *$ & $-0.09 * * *$ & $-0.09 * * *$ \\
\hline $\operatorname{prsurpl}_{t-4}, c a b_{t-4}$ & $0.25^{* *}$ & $0.39 * * *$ & $0.26 * *$ & $0.41 * *$ \\
\hline$p_{\text {ol }}$ & $-0.02 * * *$ & $-0.01 * *$ & $-0.01 * * *$ & $-0.01 * *$ \\
\hline Obs. & 67 & 67 & 67 & 67 \\
\hline Adj. R-squared & 0.33 & 0.28 & 0.26 & 0.23 \\
\hline $\begin{array}{l}\text { Breusch-Godfrey Serial Correlation } \\
\text { LM Test (lag4) }\end{array}$ & $p=0.91$ & $p=0.74$ & $p=0.49$ & $p=0.53$ \\
\hline Breusch-Pagan-Godfrey test & $p=0.08$ & $p=0.06$ & $p=0.01$ & $p=0.05$ \\
\hline
\end{tabular}

According to the results, prior to the breaking points, Ukraine's fiscal policy was close to an active-sustainable or a neutral state. After the identified points, fiscal policy turned passive relative to economic trends. The 302006 is notable as it was the 
starting point of the strongest cyclical economic growth in Ukraine's history (Figure 1). This period of strong economic growth in Ukraine was driven by the robust growth of the global economy and, consequently, the sharp rise in global commodity prices. The growth was fastest in the commodity markets that make up Ukraine's major exports .

Figure 1. The debt ratio and the output gap in Ukraine

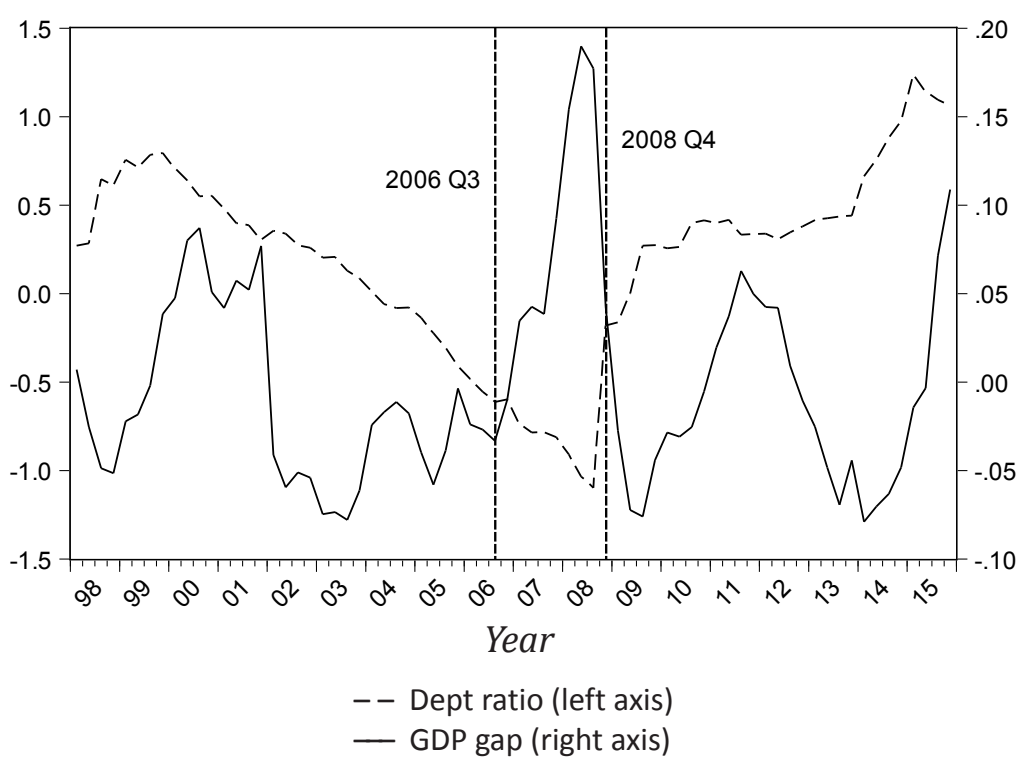

This period of cyclical economic growth was marked by the overheating of the global economy and finished with the global financial crisis and the material decline in global output. The boom period for Ukraine's economy at the end of 2006 resulted in fiscal policy switching into passive mode and remaining in that mode until 4Q 2015. From 3Q 2006 to 4Q 2008, under conditions of economic growth and decreasing debt, this meant increasing the budget deficit. However, the collapse of the global economy and international capital markets and the resulting lack of external financing for Ukraine led to the uncontrolled growth of public debt, which led the passive fiscal policy regime to remain for some time. Two major endogenous factors prompted the exponential growth of Ukraine's public debt. Ukraine's passive fiscal policy approach in 2006-2008 made it impossible to form reserves for future economic downturns (a narrower fiscal space) and contributed to the accumulation of debt. Meanwhile, inexpensive financial resources on the overheated international capital markets encouraged the government to increase Ukraine's external debt, which was negatively affected after the devaluation of the hryvnia in 2008-2009.

Thus, the switching of fiscal policy, whereby the budget deficit is tied to the level of debt and cannot be used to finance counter-cyclical actions, took place not during the crisis that began in late 2008, but during the period of economic growth. The switch was caused by a non-prudential government policy that was dependent on steady economic growth and a fixed exchange rate.

The Least Squares with Breaks approach enables us to match the prevailing trends with breaks in time, but that approach does not allow an analysis of the economic factors that caused the policy change. To analyze changes to fiscal policy regimes depending on debt dynamics and the phase of the business cycle, we have run regressions with splines. For the output gap, the spline was set at zero to observe the behavior of the FPRF coefficients during periods of economic overheating and recessions. Similarly, we established a spline for debt growth. For the level of public debt, the spline was set at the mean value for the 1998-2015 period. The results of the estimates (Table 5) indicate that relative to the business cycle phase, fiscal policy switched to passive mode during periods of a positive output gap. During economic recession, fiscal policy is neutral - there is no counter-cyclical reaction and no definitive correction of the budget deficit in-line with changes to the level of debt. This explains why in previous models with structural breaks, Ukraine's fiscal policy was shown to be in a neutral mode from 1998 to Q3 2006 - for most of this period, Ukraine had a negative output gap. Regressions with the splines on the debt measures indicate that the fiscal policy is generally sustainable and increases its responsiveness to debt changes with the growth in the debt burden. At the same time, conditional on the level of debt, there is no statistically significant relationship between the budget deficit and the business cycle. Regardless of the level of debt, fiscal policy is pro-cyclical, although this result is not statistically significant. 


\section{Table 5. The fiscal policy reaction function with splines}

\begin{tabular}{|c|c|c|c|c|c|c|}
\hline \multirow{2}{*}{$\begin{array}{l}\text { Spline } \\
\text { Dependent variable }\end{array}$} & \multicolumn{2}{|c|}{$\begin{array}{l}\text { Negative output gap (-) } \\
\text { Positive output gap (+) }\end{array}$} & \multicolumn{2}{|c|}{$\begin{array}{l}\text { Debt decrease (-) } \\
\text { Debt increase (+) }\end{array}$} & \multicolumn{2}{|c|}{$\begin{array}{c}\text { Below average debt level } \\
(-) \\
\text { Above average debt level } \\
(+)\end{array}$} \\
\hline & prsurpl & $c a b$ & prsurpl & $c a b$ & prsurpl & $c a b$ \\
\hline Constant & $0.01 * * *$ & $0.02 * *$ & 0.01 & $0.01 *$ & 0.01 & $0.01 * *$ \\
\hline d_2010q03 & $-0.07 * * *$ & $-0.07 * * *$ & $-0.08 * * *$ & $-0.08 * * *$ & $-0.09 * * *$ & $-0.09 * * *$ \\
\hline $\operatorname{prsurpl}_{t-4} / \mathrm{cab}_{t-4}$ & $0.20 *$ & $0.30 * * *$ & 0.20 & $0.30 * * *$ & $0.22 *$ & $0.37 * * *$ \\
\hline $\mathrm{pol}_{t}$ & $-0.01 * * *$ & $-0.01 * * *$ & $-0.02 * * *$ & $-0.01^{* *}$ & $-0.01 * * *$ & $-0.01 * *$ \\
\hline$g a p_{t-4}(-)$ & 0.19 & 0.16 & -0.11 & -0.1 & -0.12 & -0.10 \\
\hline $\operatorname{gap}_{t-4}(+)$ & $-0.25^{* * *}$ & $-0.19 * * *$ & -0.02 & 0.01 & -0.01 & -0.01 \\
\hline$d_{-} d e b t_{t-4}(-)$ & 0.05 & 0.03 & 0.04 & 0.04 & $0.03 * *$ & 0.04 \\
\hline$d_{-} d e b t_{t-4}(+)$ & $0.03 * * *$ & $0.04^{*}$ & $0.03 * * *$ & $0.04 * * *$ & 0.07 & 0.06 \\
\hline Obs. & 68 & 68 & 68 & 68 & 67 & 67 \\
\hline Adj. R-squared & 0.31 & 0.3 & 0.27 & 0.28 & 0.28 & 0.29 \\
\hline Autocorrelation in residuals test & 0.11 & 0.37 & 0.01 & 0.17 & 0.08 & 0.50 \\
\hline Heteroscedasticity test & 0.26 & 0.24 & 0.38 & 0.25 & 0.31 & 0.33 \\
\hline
\end{tabular}

The models with splines indicate that the switching of fiscal policy takes place under the influence of the business cycle phase (from neutral to passive), while debt growth only increases the sustainability of fiscal policy. As mentioned in the discussion of the existing literature, the asymmetry of fiscal policy regimes relative to the output gap holds risks for fiscal sustainability. A pro-cyclical fiscal policy during periods of economic growth and the lack of pro-cyclicality during downturns leads to a narrowing of the government's fiscal space and creates the conditions for an accumulation of debt in the future, which is not always accompanied by positive economic trends. The sustainability of fiscal policy during periods of a positive output gap (debt reduction and increased budget deficit) cannot always compensate for the negative impact of the asymmetry. The asymmetry in response to budget deficits is not complete. During periods of a negative output gap, fiscal policy is neutral. On the one hand, this can help reduce debt, because during economic downturns the government does not increase the budget deficit. On the other hand, the lack of counter-cyclical policy prolongs the economy's time in depression, which affects public finances and can increase the level of debt.

While running the regressions with splines we first define the thresholds for regime switching at our own discretion and we believe the FPRF coefficients are homogeneous in the sub-samples of the data we have chosen. However, this approach is subjective and it makes sense to allow the data to identify the conditions of regime switching. For this, we apply the LSTR model (4), which allows us to test several potential transition variables for the presence of nonlinearities between the FPRF variables. Parameter $\gamma$ controls the slope of the transition function according to Teräsvirta (2004), when $\gamma \rightarrow \infty$ the LSTR1 model approaches the Markov switching regression model with two regimes that have equal variances. The LSTR2 model, in this case, converges to switching the regression model with three regimes such that the outer regimes are identical and the middle regime is different from the other two. Thus, in constructing the LSTR model we can identify the variables that induce regimeswitching and assume a slower transition between the regimes than in the Markov switching models.

As noted in the description of the methodology, as candidates for the transition variables we tested the ratio of public debt to GDP (debt) and the output gap (gap). The testing methods are described in Teräsvirta (1994, 1998). ${ }^{3}$ In our results, we present estimations based on those transition variables, which made it possible to identify the nonlinear relationships between the variables in the FPRF. 
Table 6. LSTR1 models of FPRF

\begin{tabular}{|l|}
\hline Dependent variable \\
\hline Transition variable \\
\hline Constant \\
\hline$d_{-} 2010 q 03$ \\
\hline pol ${ }_{t}$ \\
\hline prsurpl \\
\hline$d$ debt $_{t-4} / \mathrm{cab}_{t-4}$ \\
\hline gap \\
\hline$\gamma$ \\
\hline $\mathrm{C} 1$ \\
\hline
\end{tabular}

Obs.

Adj. $R^{2}$

Test of No Error

Autocorrelation (p-value)

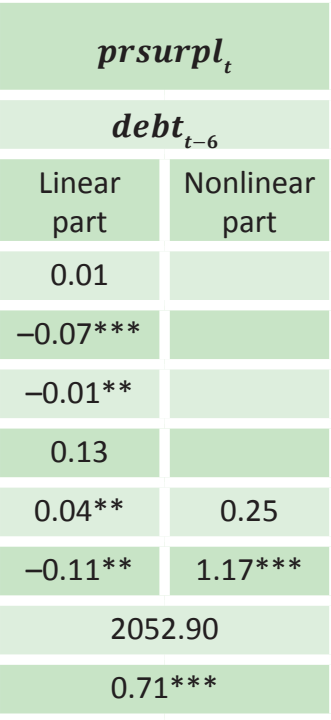

65

0.53

\begin{tabular}{|c|c|}
\hline $\operatorname{lag} 1=$ & $\operatorname{lag} 2=$ \\
\hline 0.94 & 0.98 \\
\hline $\operatorname{lag} 3=$ & $\operatorname{lag} 4=$ \\
\hline 0.99 & 0.98 \\
\hline
\end{tabular}

\begin{tabular}{|c|c|}
\hline \multicolumn{2}{|c|}{$\boldsymbol{p r s u r p l}_{\boldsymbol{t}}$} \\
\hline \multicolumn{2}{|c|}{$\boldsymbol{g a p}_{\boldsymbol{t - 8}}$} \\
\hline $\begin{array}{c}\text { Linear } \\
\text { part }\end{array}$ & $\begin{array}{c}\text { Nonlinear } \\
\text { part }\end{array}$ \\
\hline $0.01^{* * *}$ & -0.01 \\
\hline-0.01 & \\
\hline$-0.01 * * *$ & \\
\hline 0.20 & \\
\hline $0.11^{*}$ & -0.10 \\
\hline-0.10 & $0.70^{* *}$ \\
\hline \multicolumn{2}{|c|}{7.40} \\
\hline \multicolumn{2}{|c|}{$0.07^{* * *}$} \\
\hline
\end{tabular}

63

0.43

\begin{tabular}{|c|c|}
\hline $\operatorname{lag} 1=$ & $\operatorname{lag} 2=$ \\
0.1 & 0.14 \\
\hline $\operatorname{lag} 3=$ & $\operatorname{lag} 4=$ \\
0.3 & 0.41
\end{tabular}

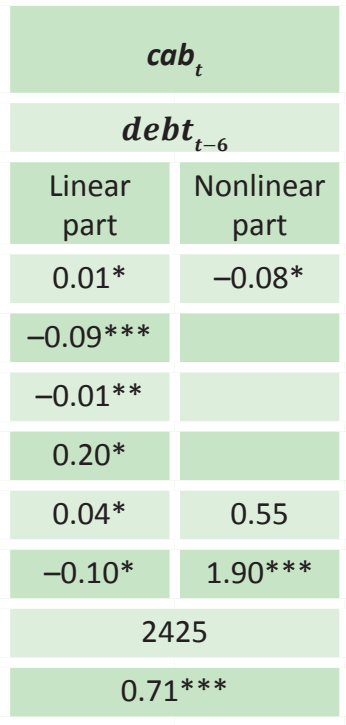

65

\subsection{5}

\begin{tabular}{|c|c|}
\hline $\operatorname{lag} 1=$ & $\operatorname{lag} 2=$ \\
0.29 & 0.44 \\
\hline $\operatorname{lag} 3=$ & $\operatorname{lag} 4=$ \\
0.59 & 0.75
\end{tabular}

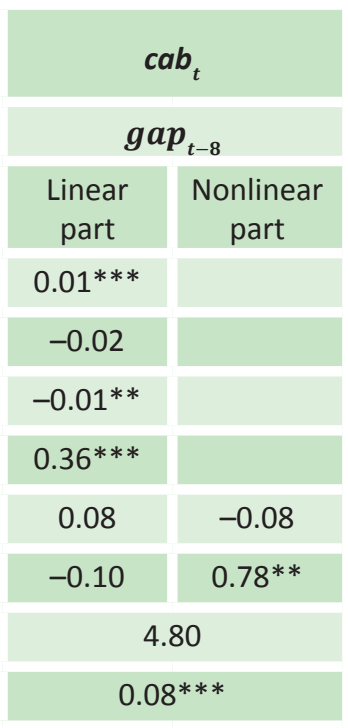

63

0.38

\begin{tabular}{|c|c|}
\hline \multicolumn{2}{|c}{0.38} \\
\hline $\operatorname{lag} 1=$ & $\operatorname{lag} 2=$ \\
0.41 & 0.58 \\
\hline $\operatorname{lag} 3=$ & $\operatorname{lag} 4=$ \\
0.63 & 0.84
\end{tabular}

Table 6 outlines the results of modeling the FPRF using the LSTR approach. The tests for nonlinearity with the use of transition variables described above constantly preferred the LSTR1 models. This means fiscal policy has two regimes, one of which is formed after a transition variable (nonlinear part) reaches a certain value. A set of tests for nonlinearities allowed us to identify two types of transition variables: the public debt to GDP ratio with a six-quarter lag and GDP with an eightquarter lag. The models for the primary (prsurpl) and cyclically adjusted budget deficit (cab) yielded approximately the same results - after crossing the transition variables with high thresholds $(C(1)$ for gap $=0.08, \max =0.18 ; C(1)$ for debt ratio $=0.71$, $\max =1.23$ ), fiscal policy switches over to an active regime. The gamma coefficients show rapid change between regimes when the transition variable is $d e p t_{t-6^{\prime}}$, while gap $p_{t-8}$ causes a relatively slow change. The statistical insignificance of $\gamma$ is justified by the fact that for large values of gamma and a small data sample, it is difficult to determine the curvature of the transition function because it requires a large number of observations near the $\mathrm{C} 1$ point. This increases the standard errors of $\gamma$. Another point is that the standard t-statistic cannot be interpreted correctly since it is designed to test the hypothesis $\gamma=0$, while in LSTR $\gamma$ is restricted: $\gamma^{s}>0$ (Teräsvirta 2004).

The thresholds for fiscal policy regime-switching and the transition functions of LSTR1 regressions are presented in Appendix 1 . These charts reflect the probability of the FPRF to be in the nonlinear part of the model, or in other words, they allow the identification of periods of FPRF switching during an active fiscal policy regime. Since the thresholds for the transition variables are relatively high, switches to fiscal policy in an active state are rare and short-lived.

The debt level threshold for fiscal policy changes in an active state (counter-cyclical and unsustainable) coincides with the results in Abiad and Ostry (2005), where they demonstrated that in emerging markets, fiscal policy becomes unsustainable after the debt-to-GDP ratio exceeds 50-60\%. The threshold estimated by the LSTR1 model for Ukraine is: $e^{0.71} / 4=0.5$.

It is important to note that the logic of fiscal policy regime-switching in Ukraine assumes the feasibility of the LSTR2 model for its description. According to our results, regime-switching takes place during the peak business cycle and debt levels. If there is a constant negative correlation between the business cycle and debt, the periods of high debt must be accompanied by low output gaps, and vice versa. This would mean that fiscal policy switches over to an active regime in two cases: when the debt ratio is high ${ }^{4}$ (low output gap) and when the debt ratio is low (high output gap). The attempt to describe Ukraine's FPRF using a three-regime model (LSTR2) was not successful owing to a low statistical significance of the coefficients. We attribute this to the lack of a negative significant correlation between the debt level and the business cycle for the significant part of our sample.

${ }^{4}$ Under high and low, we mean above or below a certain threshold level that is statistically significant. 
We also tested for the presence of nonlinear relationships in Ukraine's FPRF provided only one variable switches $\left(d \_d e b t t-4\right.$, or gapt-4). Based on the results, we ran several LSTR1 regressions that are not reported in this article. Those models suggest the coefficients of the business cycle are more likely to switch, while the debt ratio coefficients are generally monotonous. This finding confirms the results of the spline regressions (Table 5), which pointed to the radical switch of the output GDP gap coefficients during different economic phases. However, the LSTR1 models also point to the fact that Ukraine's fiscal policy was not in a passive state for the full range of positive values of the business cycle. At extremely high values of the GDP gap, policy shifted to an active regime.

The shift of fiscal policy from passive to active mode at a high GDP gap in our view is explained by the fact that the budget deficit cannot be expanded for long under conditions of economic growth. Eventually, the fiscal balance must be corrected, which would have features of counter-cyclicality. In addition, if the economic growth is accompanied by a decrease in debt levels, the debt becomes problematic for a government that pays little attention to it. Switching over fiscal policy in an active regime with a high debt ratio corresponds to the "fiscal fatigue" phenomenon described in Ghosh et al. (2013). It can be explained by the fact that after a certain threshold, the government is no longer able to reduce the budget deficit and no longer responds to high debt levels.

\section{CONCLUSIONS AND POLICY IMPLICATIONS}

This study explores the fiscal policy reaction function with switching regimes in Ukraine.

The application of alternate approaches to testing breaks in the data allows us to identify that the policy switched over to passive mode in 3Q 2006. We found that Ukraine's fiscal policy remained largely passive over 2006-2015, but it occasionally switched over to active mode during periods of a high output gap and debt-to-GDP ratio.

In addition, we document an incomplete asymmetry in the response of the budget balance to the phase of the business cycle: fiscal policy is pro-cyclical during periods of economic growth, but neutral in recession. Therefore, our findings explain the exponential growth in debt over the last decade and confirm that the pro-cyclicality prevented the creation of sufficient fiscal space to maintain an active fiscal policy during a recession.

All the findings are robust with respect to the choice of estimation techniques and measures of the budget deficit and are in-line with previous empirical works. Like Mendoza and Ostry (2007), we found that Ukraine's fiscal policy switches over to an active regime after the debt-GDP ratio crosses the $50 \%$ threshold and this switch occurs with a high output gap. Unlike Abiad and Ostry (2005), but in-line with Bohn (2005), our findings suggest fiscal policy strengthens in response to debt. The identified nonlinear effects are consistent with the so-called "fiscal fatigue" described by Ghosh et al. (2013). This implies that fiscal policy switches to an unsustainable regime at low and high levels of public debt, when the government becomes incapable of reducing the budget deficit and does not respond to growing debt after a certain threshold.

From a practical point of view, the identification of the incomplete asymmetry in the response of fiscal policy during different phases of the economic cycle (pro-cyclical fiscal policy in an upturn and neutral in a downturn) resulted in an additional increase in debt in a downturn and a missed opportunity to create fiscal space during an upturn. As a result, because debt levels were high, the government was not able to use fiscal stimulus during the recession in 2014-2016.

A resolution to this situation is to (1) in the medium-run consolidate the budget to reduce and stabilize the level of debt; and (2) develop fiscal rules that restrict pro-cyclical fiscal policy during future economic boom periods. 


\section{APPENDIX 1.}

The probability of FPRF switching to a nonlinear regime (active fiscal policy) and the dynamics of transition variables compared with the estimated thresholds

Transition function. Depended variable - prsurpl. Transition variable $-\operatorname{debt}(t-6)=0.71$

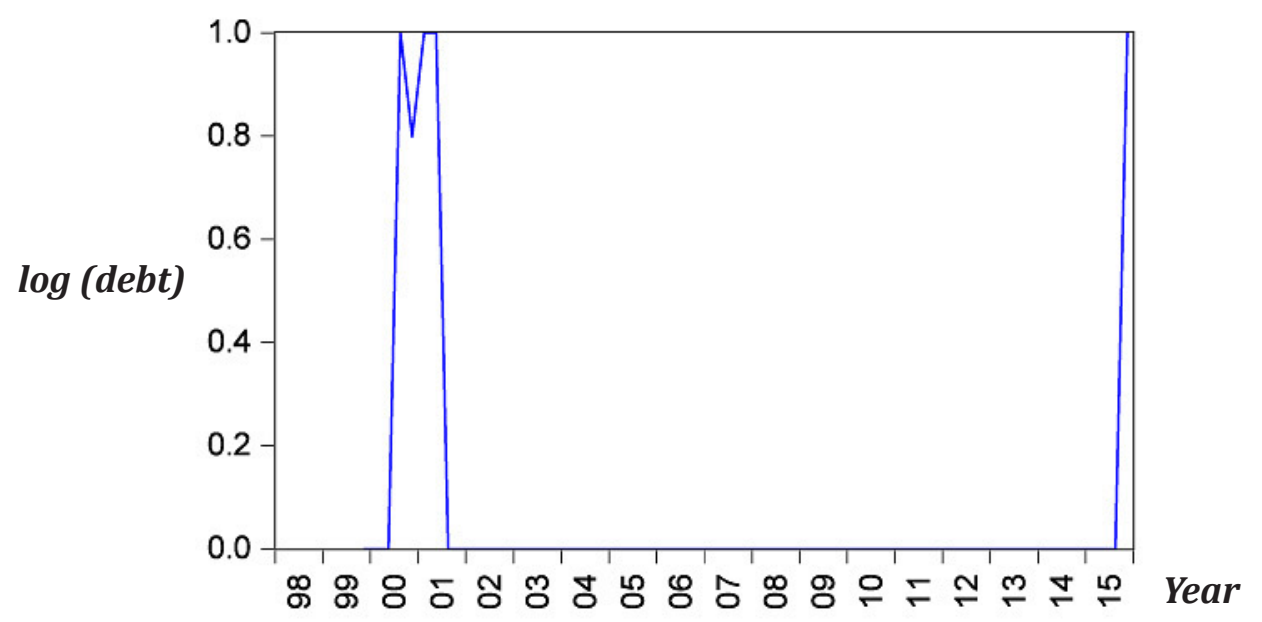

Transition function. Depended variable $-\boldsymbol{c a b}$. Transition variable $-\operatorname{debt}(\boldsymbol{t}-6)=0.71$

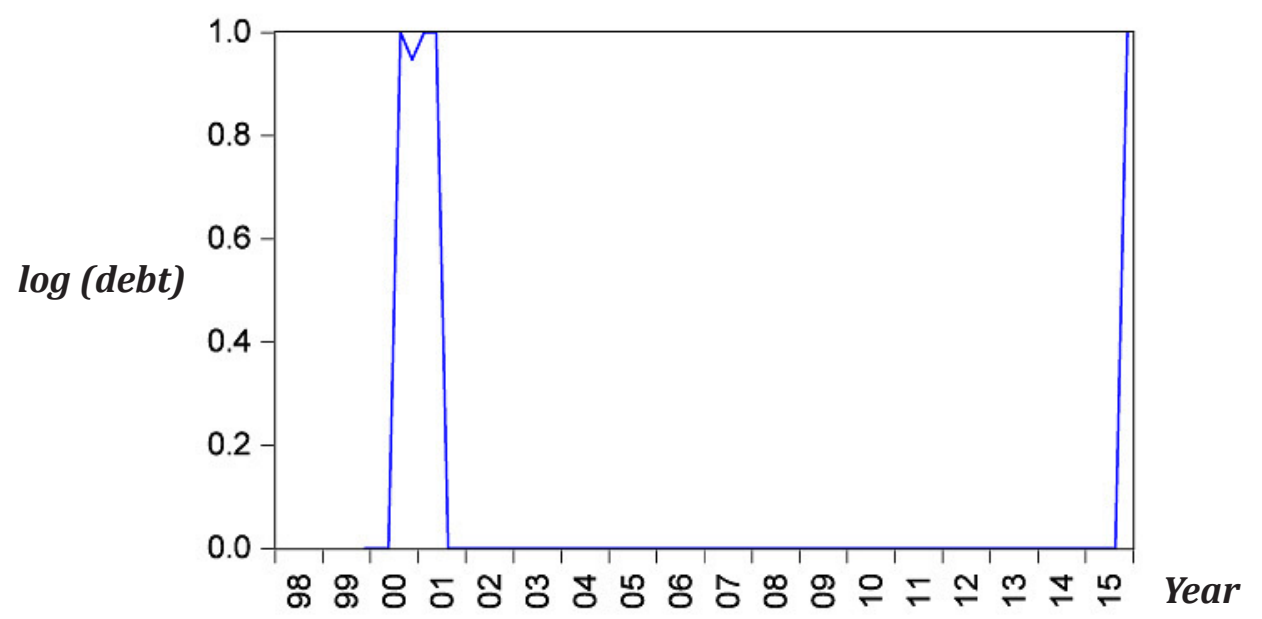

debt

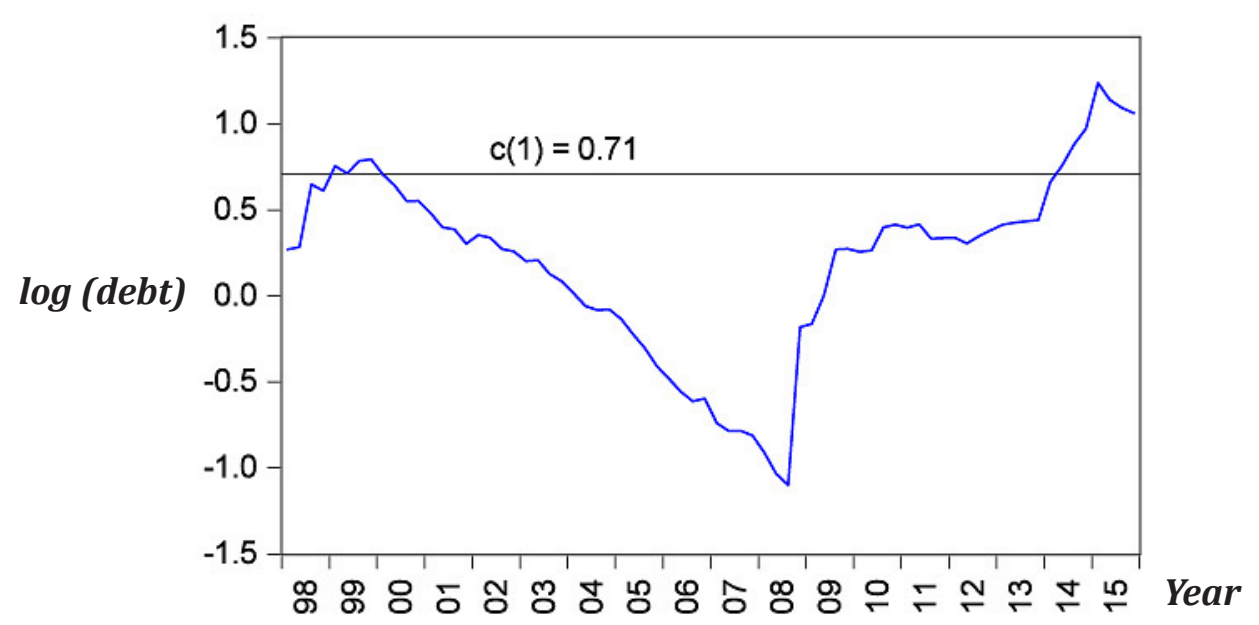


The probability of FPRF switching to a nonlinear regime (active fiscal policy) and the dynamics of transition variables compared with the estimated threshold

Transition function. Depended variable - prsurpl. Transition variable $-g a p(t-8)=0.08$

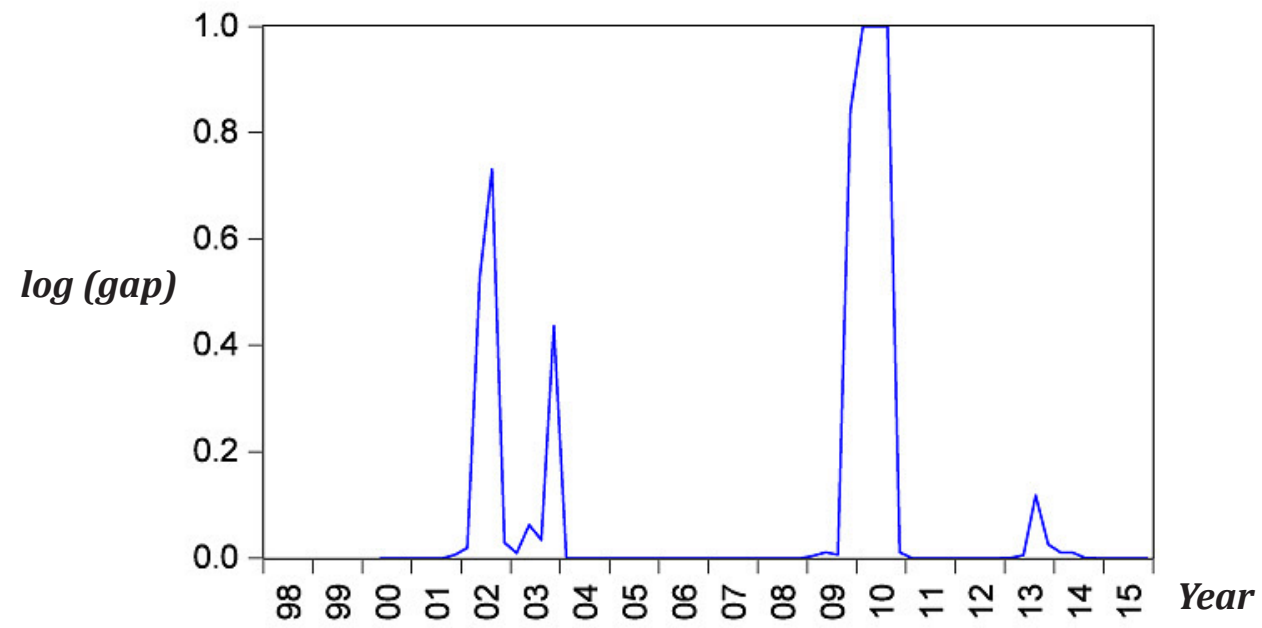

Transition function. Depended variable $-c a b$. Transition variable $-g a p(t-8)=0.08$

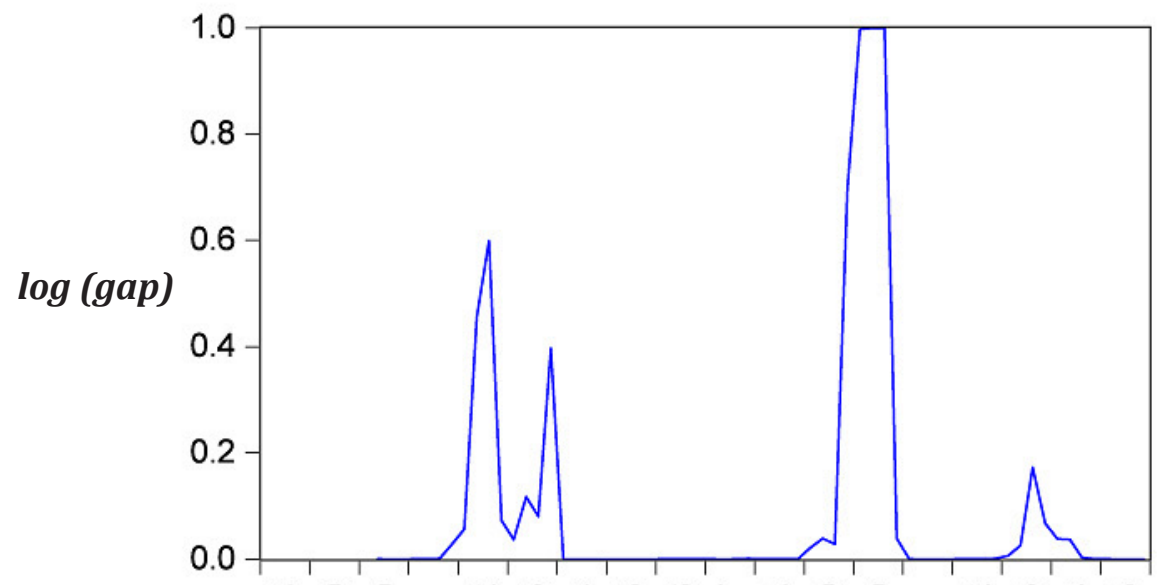

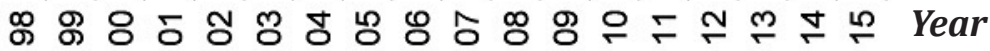
GPD cycle

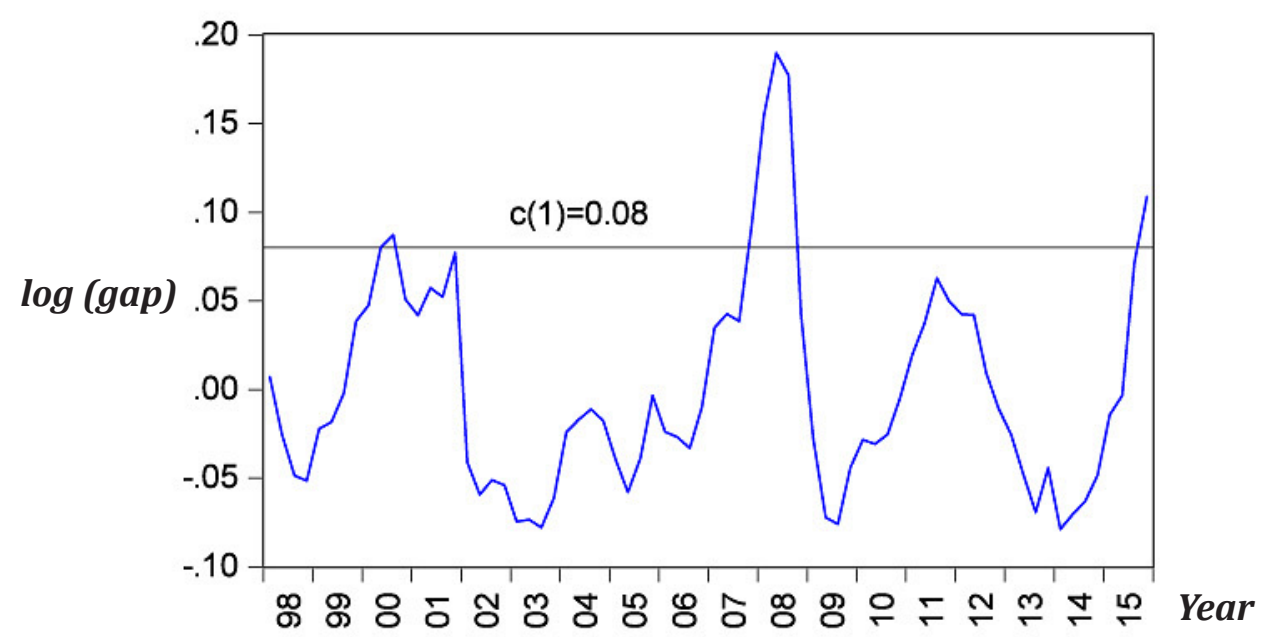




\section{References}

- Abiad A., Ostry J. (2005). Primary Surpluses and Sustainable Debt Levels in Emerging Market Countries. Working Paper, No. PDP / 05-6, IMF, Washington D.C.

- Bohn H. (1998). The Behavior of U.S. Public Debt and Deficits. Quarterly Journal of Economics, Vol. 113, No. 3, pp. $949-963$. https://doi.org/10.1162/003355398555793

- Bohn H. (2005). The Sustainability of Fiscal Policy in the United States. CESifo Working Paper Series, No. 1446.

- Bohn H. (2007). Are stationary and cointegration restrictions really necessary for the intertemporal budget constraint? Journal of Monetary Economics, Vol. 54, No. 7, pp. 1837-1847.

- Budina N., Wijnbergen, S. (2008). Quantitative approaches to fiscal sustainability analysis: a case study of Turkey since the crisis of 2001. World Bank Economic Review Vol. 23, No.1, pp. 119-140. https://doi.org/10.1093/wber/lhn011

- Burger P., Marinkov M. (2012). Fiscal rules and regime-dependent fiscal reaction functions: the South African case. OECD Journal on Budgeting, Vol. 12, No. 1, pp. 1-29. https://doi.org/10.1787/budget-12-5k9czxjth7tg

- Burger P., Stuart I., Jooste C.,Cuevas A. (2011). Fiscal sustainability and the fiscal reaction function for South Africa. Working Paper, No. 11-69, IMF, Washington D.C.

- Claeys P. (2008). Rules, and their effects on fiscal policy in Sweden. Swedish Economic Policy Review Vol. 15, No. 1, pp. 7-48.

- de Mello L. (2005). Estimating a fiscal reaction function: the case of debt sustainability in Brazil. Working Papers, No. 423, OECD Economics Department. https://doi.org/10.1787/556325773018

- Favero C., Marcellino M. (2005). Modelling and Forecasting Fiscal Variables for the Euro Area. Oxford Bulletin of Economics and Statistics, Vol. 67, No. 1, pp. 755-783. https://doi.org/10.1111/j.1468-0084.2005.00140.x

- Favero C., Monacelli T. (2005). Fiscal policy rules and regime (in) stability: evidence from the U.S. Working Paper, No. 282, IGIER.

- Gali J., Perotti R. (2003). Fiscal policy and monetary integration in Europe. Discussion Paper No. 3933, CEPR.

- Ghosh A., Kim J., Mendoza E., Ostry J., Qureshiet M. (2013). Fiscal Fatigue, Fiscal Space and Debt Sustainability in Advanced Economies. Economic Journal, Royal Economic Society 02, F4-F30, 02. https://doi.org/10.1111/ecoj.12010

- IMF (2015). Fiscal Monitor - Now Is the Time: Fiscal Policies for Sustainable Growth IMF, Washington D.C.

- Leeper E. (1991). Equilibria under active and passive monetary and fiscal policies. Journal of Monetary Economics, Vol. 27, No. 1, pp. 129-147. https://doi.org/10.1016/0304-3932(91)90007-B

- Legrenzi G., Milas C. (2013). Modelling the fiscal reaction functions of the GIPS based on state-varying thresholds. Economics Letters, Vol. 121, No. 3, pp. 384-389. https://doi.org/10.1016/j.econlet.2013.09.011

- Mendoza E., Ostry J. (2007). International evidence on fiscal solvency: Is fiscal policy responsible? Working Paper, No. 0756, IMF, Washington D.C.

- Penalver A., Thwaites G. (2006). Fiscal Rules for Debt Sustainability in Emerging Markets: The Impact of Volatility and Default Risk. Working Paper, No. 307, Bank of England. https://doi.org/10.2139/ssrn.933299

- Teräsvirta T. (1994). Specification, estimation, and evaluation of smooth transition autoregressive models, Journal of the American Statistical Association, Vol. 89, No. 425, pp. 208-218.

- Teräsvirta T. (1998). Modeling economic relationships with smooth transition regressions, in: A. Ullah and D. E. Giles, eds., Handbook of Applied Economic Statistics, New York: Dekker.

- Teräsvirta T. (2004). Smooth transition regression modeling, in: H. Lütkepohl, and M. Krätzig, eds., Applied Time Series Econometrics, Cambridge University Press. https://doi.org/10.1017/СB09780511606885.007 